\title{
Guarigione di un cieco (Mc 8,22-26) nel contesto del Vangelo di Marco
}

\author{
Cure of a Blind Man (Mark 8:22-26) in the Context of the Gospel \\ according to Mark
}

\author{
TOMASZ BARTŁOMIEJ BĄK \\ Institute of Biblical Studies, John Paul II Catholic University of Lublin \\ e-mail: tomciobak@gmail.com \\ ORCID: 0000-0003-0328-0282
}

\begin{abstract}
Summary: The Gospel according to Mark strives after providing the answer to two fundamental questions who Jesus is and who his disciple should be. Thus, the Evangelist makes some attempts to depict the identity of Jesus emphasizing his being the Son of God (cfr. Mk 1:1; 15:39). What is more, setting the description of the road leading to Jerusalem in the centre of his literary work, the author of the gospel highlights the identity of the Jesus' disciple, who is not always able to understand the one, who called him.

The aim of this article is to present the way how the pericope about the cure of a blind man (Mk 8:22-26) is depicted in the dynamism of the whole gospel and how it corresponds with effort being made with the aim of answering the questions: who Jesus is and who his disciples should be. The text, which is written in accordance with the principles of synchronic analysis, is comprised of such sections:

I Introductory issues (distinguishing of the pericope as the whole; textual criticism; defining of the internal structure; synoptic comparison);

II. Exegetical analysis;

III. The significance of the pericope in the context of the whole Gospel;

In the analysis of the cure of a blind man (Mk 8:22-26) the disciples are presented as those who seem to remain "outside" Christ mystery. The pericope corresponds perfectly with the fact that they possess eyes that do not see (cfr. Mk 8:18) and they do not yet understand (cfr. Mk 8:21). Not only does Jesus open the eyes of the blind man but also wants to open the eyes of his disciples. Two stages of healing reveal that regaining sight fully is preceded by the period of "shortsightedness" when the disciple has a vision but still blurred. He follows Jesus to Jerusalem, though, he does not understand who Jesus is. The moment when he completely opens his eyes and understands becomes possible in the context of the Paschal Mystery.
\end{abstract}

KEYWORds: cure, blind, Gospel according to Mark, road to Jerusalem, identity of disciple, Mk 8:22-26

1 racconto della guarigione di un cieco (Mc 8,22-26) è caratterizzato da due temi, entrambi importanti per tutta l'opera marciana e strettamente collegati tra loro: il primo è la questione dell'identità di Gesù e il secondo è il discepolato. Le parole: "Non capite ancora?" $(8,21)$ che precedono il nostro brano e la 
duplice domanda di Gesù: "Chi dice la gente che io sia?" $(8,27)$ e "voi che dite che io sia?" $(8,29)$ costituiscono per così dire la cornice del nostro racconto. La domanda "chi è Gesù?" occupa infatti un posto particolare in questo vangelo e si coglie da subito uno speciale interesse per l'identità di Gesù (cfr. 1,1), che si protrae sino ai capitoli finali (cfr. 15,39). Nel nostro brano $(8,22-26)$, Gesù si rivela come un taumaturgo. Soltanto in questo racconto, il miracolo di Gesù si svolge in due tappe. Due volte impone le mani sull'uomo malato e gli rivolge anche una domanda sorprendente: "Vedi qualcosa?" $(8,23)$. Gesù si rivela come colui che è capace di aprire gli occhi del cieco.

Vi si ritrovano anche altri elementi importanti quanto al secondo tema, quello del discepolato. In Marco i discepoli seguono Gesù fin dagli inizi della sua attività (cfr. 1,16-20), sono testimoni di tutto ciò che egli ha detto e compiuto, godono di un rapporto privilegiato con Lui. Nel nostro racconto non sono però in primo piano. Soltanto all'inizio, quando l'evangelista dice che giunsero a Betsaida $(8,22)$, si parla della presenza dei discepoli. Non parlano, non dicono niente, se ci sono, restano in silenzio per tutto il racconto. La guarigione del cieco, come vedremo, non si riferisce soltanto all'uomo malato, ma assume un grande significato anche per i discepoli, i quali non capiscono bene chi è Gesù e qual è la sua missione. Anche i loro occhi devono essere aperti da Gesù. Il fine di quest' articolo è di presentare come la pericope della guarigione di un cieco (Mc 8,22-26) si inserisce nella dinamica di tutto il Vangelo e come essa corrisponde alla domanda: chi è Gesù e chi dovrebbe essere il suo discepolo? Analizzeremo, com'è naturale, vari testi relativi al vangelo di Marco. Possiamo anzi affermare che tutti i commenti relativi alla guarigione del cieco - e citati nelle note a piè di pagina - si riferiscono in realtà a tutto il Vangelo. Manca tuttavia, a nostro avviso, un testo che esamini in modo semplice e insieme approfondito questo brano nel contesto della questione della identità di Gesù e dei suoi discepoli. Con il presente articolo, auspichiamo di dare un piccolo contributo a questo tema.

La struttura del nostro articolo è articolata nel modo seguente: I. Analisi introduttiva; II. Analisi esegetica; III. Posizione della pericope nel contesto. Utilizzeremo soprattutto l'approccio sincronico, accettando quindi il testo così come si presenta nel vangelo, per scoprirne il contenuto e il messaggio nascosti.

\section{Analisi introduttiva}

Nella analisi introduttiva affrontiamo principalmente quattro questioni: 1. La delimitazione del brano secondo i criteri delle persone, del luogo, del tempo e delle tematiche; 2. La critica testuale; 3. La struttura interna; 4. Il paragone sinottico. 


\subsection{La delimitazione della pericope}

Cominciamo la nostra analisi collocando il brano di Mc 8,22-26 nel suo contesto immediato seguendo quattro criteri: del tempo, del luogo, delle persone e delle tematiche.

Nel brano precedente $(8,14-21)$ troviamo l'ammonimento di Gesù che esorta a guardarsi dal lievito dei farisei e di Erode. Gesù sta con i suoi discepoli che hanno dimenticato di prendere dei pani e ciò provoca una discussione, durante la quale Gesù parla del lievito dei farisei e di Erode. La scena ci rivela chiaramente l'incapacità dei discepoli a comprendere il Maestro.

L'azione del nostro brano (8,22-26) si svolge quando giunsero a Betsaida (v. 22), cioè sull'altra riva del mare di Galilea. Il tempo non è precisato. All'inizio della scena è presente un buon numero di persone: Gesù, i suoi discepoli, un cieco e coloro che lo avevano condotto da Lui. Poi, dal v. 23, Gesù resta solo con il cieco, al di fuori del villaggio. Il tema del nostro brano è diverso dal precedente e si concentra attorno alla guarigione del cieco. Si vede chiaramente che il tempo, il luogo, le persone e la tematica sono diversi da Mc 8,14-21.

Anche il brano che segue $(8,27-30)$ viene presentato come una scena successiva, nella quale Gesù con i suoi discepoli partono verso $i$ villaggi intorno a Cesarèa di Filippo (v. 27), si incamminano cioè verso il nord. Come avviene in Mc 8,14-21, anche qui Gesù è accompagnato soltanto dai suoi discepoli. Il tema principale del brano è la professione di fede di Pietro (v. 30).

Queste brevi considerazioni ci portano alla conclusione che la nostra pericope costituisce un'unità narrativa autonoma, ben distinta da ciò che la precede e da quanto la segue.

\subsection{Critica testuale}

In questa parte del lavoro ci concentreremo sulle diverse proposte di lettura della pericope. Va detto anzitutto che non vi sono grandi difficoltà testuali. Passeremo perciò in rasssegna soltanto i casi più significativi.

Al v. 22 alcuni manoscritti (tra cui il Codex Bezae) modificano il nome della città e scrivono: $\epsilon$ lı $B \eta \theta \alpha \nu\llcorner\alpha \nu$. Già la critica testuale esterna (vi sono pochi manoscritti, il Codex Bezae è all'incirca del VI sec.) indica che il testo originale sembra essere: $\epsilon$ ¿̇ $B \eta \theta \sigma \alpha i ̈ \delta \alpha \nu^{1}{ }^{1}$. Il nome è stato modificato probabilmente a causa

1 Da notare che in The Greek New Testament (ed. Metzger) non si registra il cambiamento del

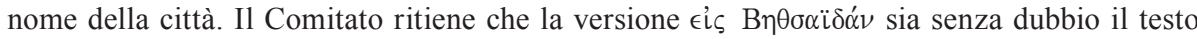
originale. 
di Gv 1,28, dove viene citata Betania al di là del Giordano, dove Giovanni stava battezzando.

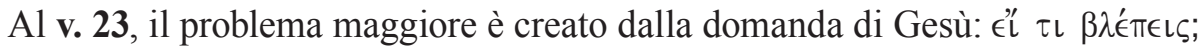
che in alcuni manoscritti (per es. $\mathrm{A} \mathrm{D}^{2} \mathrm{~L} \mathrm{~W}$ ) viene presentata con il discorso indiretto: $\epsilon l \iota \iota \beta \lambda \lambda^{\prime} \pi \epsilon l$. Nel greco classico, la particella interrogativa $\epsilon \dot{l}$ segnala l'interrogativo indiretto, nel greco non classico invece viene usata per una domanda diretta ${ }^{2}$. Secondo gli esegeti, la versione originale: $\epsilon^{\prime l} \tau \iota \quad \beta \lambda \epsilon ́ \pi \epsilon \iota \varsigma$ ( $\epsilon$ l non classico nella domanda diretta) è stata modificata in: $\epsilon^{\prime \prime} \tau \iota \quad \beta \lambda \lambda^{\prime} \pi \epsilon l$ cioè hanno eliminato $-\varsigma$ per adeguare la particella $\epsilon^{\prime \prime}$ all'uso del greco classico ${ }^{3}$.

L'ultimo versetto del nostro brano, il v. 26, presenta alcune varianti della frase finale ${ }^{4}$. Secondo Metzger, la più vicina all'originale appare la lezione: $\mu \eta \delta^{\prime} \epsilon$

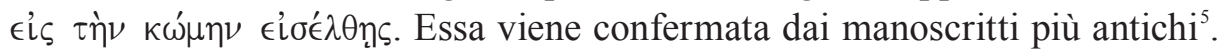

Riguardo alla critica testuale di Mc 8,22-26, possiamo affermare che le lezioni presentate nell'apparato critico non modificano sostanzialmente il significato del brano.

\subsection{L'analisi sintattica e la struttura del testo}

Per comprendere meglio il significato della nostra pericope è necessario precisarne dapprima la struttura il che sarà possibile mediante l'analisi sintattica. Lo stile narrativo del racconto è vivo e colorito. Tutto il brano - ad eccezione del v. 25 -

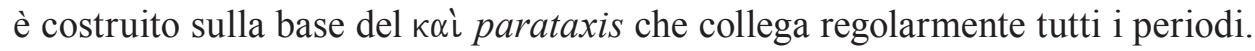

Una caratteristica dello stile marciano, anche visibile nella nostra pericope, è il cambiamento dei tempi verbali. Nel v. 22 abbiamo il presente storico, sem-

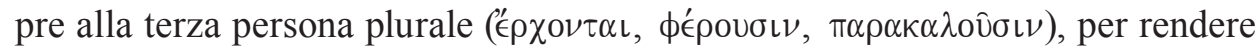
i fatti che accadono in modo vivace, come se ad essi fosse presente il narratore $^{6}$. Poi, nei versetti $23-25$ prevale l'uso dell'aoristo all'indicativo (v. 23:

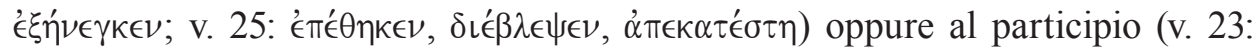

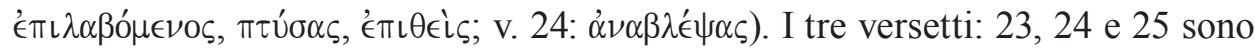
a loro volta caratterizzati anche dalla presenza del tempo imperfetto. Nel v. 23

2 Cfr. $B D R, \S 440$.

3 H. Greeven, "Mk 8,23. Analyse der Textüberlieferung", Textkritik des Markusevangeliums (ed. H. Greeven - E. Gütig) (Münster: LIT Verlag 2005) 415. Vedi anche: R.T. France, The Gospel of Mark. A Commentary on the Greek Text (The New International Greek Testament Commentary; Grand Rapids, MI - Cambridge, U.K.: Eerdmans 2002) 324.

4 Per una spiegazione più dettagliata di questo versetto vedi: J.I. Miller, "Was Tischendorf Really Wrong? Mark 8:26b Revisited", NT 28 (1986) 97-103; J.M. Ross, "Another Look at Mark 8:26", NT 29 (1987) 97-99.

5 Per tutte le versioni del v. 26 vedi: B.M. Metzger, A Textual Commentary on the Greek New Testament (Stuttgart: Deutsche Bibelgesellschaft $\left.{ }^{2} 2001\right) 84$

$6 \quad B D R, \S 321$. 


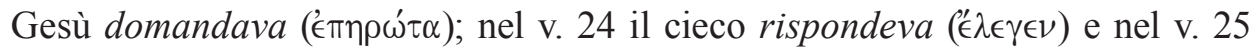

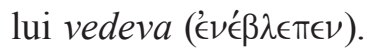

La fine del v. 23 e l'inizio del v. 24 sono collegati tra loro attraverso una "triade" di forme verbali: 1. participio aoristo attivo (v. 23: Ł̇ $\pi \theta \in i \varsigma, ~ v . ~ 24:$

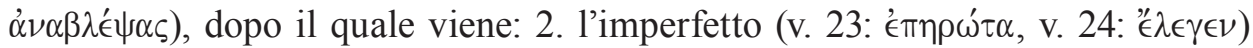
e poi: 3. l'indicativo presente attivo (v. 23: $\beta \lambda \epsilon ́ \pi \epsilon \iota \varsigma, ~ v . ~ 24: \beta \lambda \epsilon ́ \pi \omega)$.

Solo due volte, nel nostro racconto, ricorre la forma del congiuntivo aoristo: all'inizio (nel v. 22) e alla fine del brano (v. 26). Nel v. 22 le persone non indicate per nome che hanno portato il cieco, pregano Gesù di toccarlo ("丷 $\psi \eta \tau \alpha \iota)$. Nel v. 26 è invece Gesù stesso che, rimandando il cieco a casa, gli proibisce

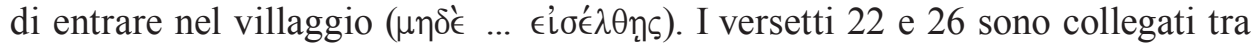
loro anche con la menzione del luogo. All'inizio del brano si dice di Betsàida, alla fine invece si parla del villaggio. Il versetto 26 conclude il racconto. Già dall'analisi delle forme verbali si vede che i vv. 22 e 26 fungono da cornice al racconto centrale, costituito dai vv. 23-25?.

L'analisi sintattica del nostro brano ci porta alla conclusione che in Mc 8,22-26 possiamo distinguere tre parti: I. Situazione iniziale (v. 22), II. Parte centrale (vv. 23-25), III. Conclusione (v. 26). Una struttura più dettagliata potrebbe essere la seguente ${ }^{8}$ :

I. La situazione iniziale:

1. L'introduzione geografica (v. 22a),

2. La presentazione del cieco e la richiesta di guarigione (v. 22b),

7 L'analisi sintattica del nostro brano ci porta ad un'osservazione molto interessante, riguardo al soggetto e all'oggetto dell'azione. Il cieco, per esempio, è dapprima oggetto dell'azione degli altri (di quelli che lo portano a Gesù - v. 22 ed anche di Gesù stesso - v. 23); poi, a cominciare dal v. 24 diventa lui il soggetto (lui ha recuperato la vista: $\alpha \nu \alpha \beta \lambda \epsilon ́ \mid \alpha \alpha \varsigma$, perciò anche lui era in

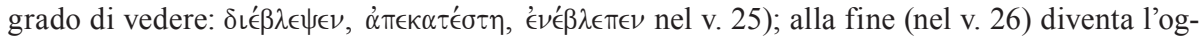
getto di $\alpha \dot{\pi} \epsilon \in \tau \epsilon \iota \lambda \epsilon \nu$ di Gesù, ma ora andrà da solo, non sarà più portato per mano, come nel v. 23. Nella seconda parte del brano il cieco recupera perciò non soltanto la sua vista ma anche la sua capacità di agire. Questo passaggio dal passivo all'attivo si vede chiaramente nel v. 25 , dove il primo soggetto è Gesù, mentre subito dopo, nella seconda parte - è il cieco. Si ripete lo stesso schema: dapprima Gesù, la cui azione viene espressa all'indicativo aoristo attivo:

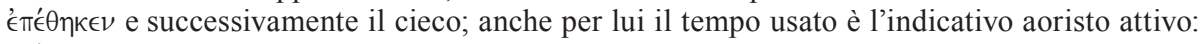
$\delta \iota^{\prime} \in \beta \lambda \in \psi \nu$.

8 Per la struttura del brano vedi per es. Lègasse, Marco, 411; R.H. Gundry, Mark. A Commentary on His Apology for the Cross (Grand Rapids, MI: Eerdmans 1993) 416; R.A. Guelich, Mark 1-8:26 (WBC 34A; Dallas, TEX: Word Books Publisher 1989) 429-430; F.J. Moloney, The Gospel of Mark. A Commentary (Peabody: Hendrickson Publishers 2002)163; B. Gianattilio, Personaggi minori e discepoli in Marco 4-8. La funzione degli episodi dei personaggi minori nell'interazione con la storia dei protagonisti (Analecta Biblica 73; Roma: Editrice Pontificio Istituto Biblico 2008) 223; A. Malina, Ewangelia wedtug świętego Marka: 1,1-8,26. Wstęp, przekład z oryginału, komentarz (Nowy Komentarz Biblijny. Nowy Testament II/1; Częstochowa: Edycja Świętego Pawła 2013) 463; per la struttura più dettagliata cfr. W. Eckey, Das Markusevangelium. Orientierung am Weg Jesu. Ein Kommentar (Neukirchen: Neukirchener Verlag 1998) 218-219. 
II. La parte centrale del racconto: la descrizione della terapia usata da Gesù (vv. 23-25), in cui si possono distinguere le parti seguenti:

1. L'allontanamento dal villaggio (v. 23ab),

2. Il gesto terapeutico di Gesù: un tocco con la saliva e l'imposizione delle mani (v. 23cd),

3. L'interrogazione (v. 23e),

4. La dichiarazione della guarigione insufficiente (v. 24),

5. La seconda imposizione delle mani (v. 25a),

6. Il ristabilimento della vista (v. 25 b).

III. La conclusione:

1. Il rimando a casa (v. 26a),

2. La proibizione di entrare nel villaggio (v. 26b).

\subsection{Il paragone sinottico}

Il racconto della guarigione del cieco di Betsaida si trova soltanto nel Vangelo di Marco. È interessante notare che Matteo e Luca seguono la narrazione marciana ma, quando arrivano a questo punto, omettono l'episodio della guarigione. In particolare, Matteo è molto vicino allo schema di Marco. Tutti e due mettono l'accento sulle tradizioni farisaiche (Mc 7,1-13; Mt 15,1-9), l'insegnamento sul puro e sull'impuro (Mc 7,14-23; Mt 15,10-20), la guarigione della figlia di una donna straniera (Mc 8,24-30; Mt 15,21-28), la seconda moltiplicazione dei pani (Mc 8,1-10; Mt 15,32-39), la richiesta dei farisei di un segno dal cielo (Mc 8,11-13; Mt 16,1-4), il lievito dei farisei e di Erode (Mc 8,14-21; Mt 16,5-12), la professione di fede di Pietro (Mc 8,27-30; Mt 16,13-20) ecc. Matteo, nel suo allinearsi a Marco omette due miracoli: 1) la guarigione di un sordomuto (Mc 7,31-37), 2) la guarigione di un cieco a Betsaida (Mc 8,22-26) .

Il fatto che entrambi i racconti succitati manchino in Mt e Lc può significare che entrambe le pericopi esistevano indipendentemente dalla fonte comune degli evangelisti. La loro somiglianza (come vedremo meglio nella terza parte dell'articolo) ci può portare alla conclusione che sono state ambedue composte dallo stesso autore oppure nate nella stessa comunità. Alcuni esegeti suppongono che potesse esistere anche una tradizione popolare delle narrazioni dei miracoli di

9 La spiegazione più probabile di questa omissione viene data da Boyd: "as in its present form it could be regarded as theologically embarrassing. Perhaps that is why neither Matthew nor Luke include it in their gospels" (W.J.P. Boyd, "Is a Basis of Fact Discernible in the Miracle Story of the Healing of the Blind Man at Bethsaida (Mk viii. 22-26)?", Papers presented to the Fifth International Congress on Biblical Studies held at Oxford, 1973 (ed. E.A. Livingstone) (Studia Evangelica VII; Berlin: Akademie Verlag 1982) 83. 
Gesù $^{10}$. Il fatto che il nostro brano (Mc 8,22-26) si ritrovi soltanto nel Vangelo di Marco può significare che è proprio questo evangelista a volergli conferire un significato particolare.

\section{La spiegazione del testo}

La seconda parte dell'articolo concerne il messaggio del testo che emerge da uno studio del significato contestuale delle parole e delle espressioni. Anche qui seguiremo la struttura indicata in precedenza.

\subsection{La situazione iniziale $(8,22)$}

La prima sezione della nostra pericope contiene: a) L'introduzione geografica $(8,22 a)$; b) la presentazione di un cieco e la richiesta di guarigione $(8,22 b)$.

\section{a) L'introduzione geografica $(8,22 a)$}

L'Evangelista comincia la pericope con l'espressione: $\kappa \alpha i$ '€ $\rho \chi 0 \nu \tau \alpha \iota$. Il verbo "venire" ('€ $\rho \chi 0 \mu \alpha \iota)$ qui usato all'indicativo presente medio, nel Vangelo di Marco indica molto spesso un cambiamento della scena, particolarmente quando viene collegato alla congiunzione $\kappa \alpha \iota^{11}$. Analizzando questa espressione nel linguaggio marciano, si vede che essa generalmente può riferirsi a due categorie di soggetti: 1) le persone diverse da Gesù e dai suoi discepoli ${ }^{12}$, 2) Gesù con gli Apostoli che non vengono indicati esplicitamente (anche le persone che avevano portato il cieco possono, in realtà, essere rimaste in silenzio insieme con loro ${ }^{13}$. Analizzando queste due categorie di soggetti del verbo " $p \chi 0 \nu \tau \alpha \iota$ si può osservare che all'inizio ricorrono quelli della prima categoria $(2,3.18 ; 5,15.35)$, per ben tre volte associati a una scena di guarigione (ad eccezione di 2,18); poi viene Gesù con i discepoli: tre volte nelle pericopi che parlano della guarigione

10 Vedi per es. Guelich, Mark, 429.

11 Per es. Mc 2,3 quando Gesù insegnava a Cafàrnao, si recarono da lui con un paralitico con il

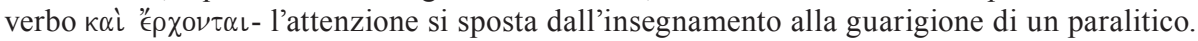
Si può osservare ancora più chiaramente questo cambiamento di scena in: Mc 10,46; 11,15.27; 14,32 .

12 Ci sono i portatori di un paralitico: Mc 2,3; le persone-probabilmente i farisei - che intavolano una discussione sul digiuno: Mc 2,18; i Gerasèni: Mc 5,15; quelli che sono usciti dalla casa del capo della sinagoga: Mc 5,35; i sommi sacerdoti, gli scribi e gli anziani: Mc 11,27; i sadducei: Mc 12,18; le donne: Mc 16,2.

13 Mc 5,38; 8,22; 10,46; 11,15.27; 14,32. 
$(5,38 ; 8,22 ; 10,46)$ e due volte a Gerusalemme $(11,15.27)$. In seguito troviamo due volte i soggetti della prima categoria $(11,27 ; 12,18)$; dopo ritorna il soggetto della seconda categoria: Gesù con i suoi discepoli, tre dei quali vengono indicati esplicitamente: Pietro, Giacomo e Giovanni $(14,32)$. E alla fine ritroviamo il soggetto della prima categoria: Maria di Màgdala, Maria di Giacomo e Salome $(16,2)$. Per maggiore chiarezza, abbiamo approntato lo schema seguente:

\begin{tabular}{|l|l|}
\hline \multicolumn{1}{|c|}{$\begin{array}{c}\text { Persone diverse da Gesù } \\
\text { e dai suoi discepoli }\end{array}$} & \multicolumn{1}{c|}{ Gesù con i suoi discepoli } \\
\hline $\begin{array}{l}\mathbf{3} \text { volte; GUARIGIONE } \\
(2,3 ; 5,15.35)\end{array}$ & $\begin{array}{l}\mathbf{3} \text { volte; GUARIGIONE } \\
(5,38 ; \underline{\mathbf{8 . 2 2}} ; 10,46)\end{array}$ \\
\hline $\begin{array}{l}\mathbf{2} \text { volte; GERUSALEMME } \\
(11,27 ; 12,18)\end{array}$ & $\begin{array}{l}\mathbf{2} \text { volte; GERUSALEMME } \\
(11,15.27)\end{array}$ \\
\hline $\begin{array}{l}\mathbf{1} \text { volta }(3 \text { nomi propri); ALLA TOMBA } \\
(16,2)\end{array}$ & $\begin{array}{l}\mathbf{1} \text { volta }(3 \text { nomi propri); GETSEMANI } \\
(14,32)\end{array}$ \\
\hline
\end{tabular}

Dal nostro schema si può osservare che il verbo " $\rho \chi 0 \nu \tau \alpha \iota$ presente in questa forma per la prima volta a Cafarnao (in Galilea), ricorre per l'ultima volta a Gerusalemme, presso la tomba vuota. Possiamo dire che proprio questa forma del verbo " $€ \chi \chi \mu \mu \alpha \iota$ indica il cammino verso Gerusalemme - il passaggio dal paralitico (Mc 2,3) alla tomba vuota (Mc 16,2). Su questo percorso in direzione della tomba vuota ritroviamo anche la nostra pericope. Proprio l'espressione $\kappa \alpha \grave{ }$ " $\rho \chi 0 \nu \tau \alpha \iota$ colloca la guarigione del cieco tra altri due miracoli: la risurrezione della figlia di Giairo (Mc 5,21-43) e la guarigione del cieco di Gerico (Mc 10,46-52). Torneremo ancora una volta su questa osservazione nella parte finale del lavoro, dedicata alla collocazione di Mc 8,22-26 nel contesto. Per ora ci limitiamo a sottolineare che il verbo $\kappa \alpha i$ ' $€ \rho \chi \nu \tau \tau \alpha \iota$, usato all'inizio della nostra pericope, può significare molto di più, non soltanto la semplice informazione che Gesù e i suoi discepoli giunsero a Betsaida. Non dimentichiamo nemmeno il presente storico, usato da Marco all'inizio della scena della guarigione, per rappresentare i fatti in modo più vivace ${ }^{14}$.

Gesù e le persone che stavano insieme a Lui sono venuti a Betsaida. Il nome della città, preso dall'aramaico, significa etimologicamente "casa del pesce", "casa dei cacciatori" o "casa del pescatore" ${ }^{15}$. Si trova a nord, sulla costa del mare di Galilea, ad est della foce del Giordano. Erode Filippo l'aveva elevata a città in onore di Augusto (nel 2 a.C.) ${ }^{16}$. Nei Vangeli la città viene citata sette

$14 \quad B D R, \S 321$.

15 Cfr. C.H. Miller - M. Wojciechowski, "Betsaida", Encyklopedia biblijna (ed. P.J. Achtemeier) (Warszawa: Vocatio 2004) 97-98.

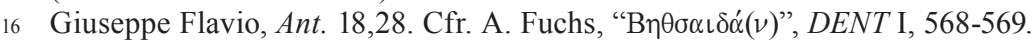


volte. Matteo e Luca la collegano con i miracoli di Gesù e con l'incredulità dei suoi abitanti. Proprio a causa della mancanza di fede nei miracoli da parte dei suoi abitanti, Betsaida viene rimproverata da Gesù: Guai a te, Corazìn! Guai a te, Betsàida! Poiché, se i prodigi che sono stati compiuti in mezzo a voi fossero stati fatti a Tiro e Sidone, da tempo in cilicio e cenere avrebbero fatto penitenza (Mt 11,21; cfr. Lc 10,13). Appold suggerisce che, nella mentalità dei lettori dei Vangeli sinottici, Betsaida poteva venir strettamente collegata con la potenza miracolosa di Gesù ${ }^{17}$. Non può essere casuale anche il fatto che Marco, nel suo Vangelo, fa un collegamento tra Betsaida e Cesarèa di Filippo ${ }^{18}$ : subito dopo la guarigione di un cieco $(8,22-26)$ Gesù passa alla questione della sua identità agli occhi dei discepoli (8, 27-30).

Nel Vangelo di Marco, Betsaida viene nominata soltanto due volte: in 6,45 e poi nel nostro versetto: $8,22 \mathrm{a}$. Nel primo passo $(6,45)$ Gesù, dopo la prima moltiplicazione dei pani (6,30-44), chiede ai suoi discepoli di far rotta verso Betsaida, ma la traversata del lago è finita in un altro luogo. I discepoli arriveranno sì a Betsaida, ma il loro viaggio sarà molto lungo. Prima li vedremo a Genèsaret $(6,53)$, poi nella regione di Tiro $(7,24)$, a Sidone $(7,31)$, nel territorio della Decàpoli $(7,31)$, dalle parti di Dalmanùta $(8,10)$. Perchè è cosí difficile arrivare a Betsaida? Myers suggerisce che la comunità dei discepoli è cieca. In 8,22 essi arriveranno infine alla meta del loro viaggio, dove Gesù mostrerà che la cecità può essere sanata ${ }^{19}$.

17 Appold parla di "fairly unified tradition that linked Bethsaida with the $\delta v v \alpha \dot{\mu} \mu\llcorner\varsigma$, the mighty works of Jesus" (M. Appold, "The Mighty Works of Bethsaida: Witness of the New Testament and Related Traditions", Bethsaida: A City by the North Sea of Galilee (ed. R. Arav - R.A. Freund) (Bethsaida Excavations Project 1; Kirksville, MO: Thomas Jefferson University Press: 1995) 236.

18 Tra queste due città esisteva probabilmente anche una strada, da percorrere a piedi (cfr. J.F. Str ange, "Beth-saida", $A B D$ I, 692-693).

19 C. Myers, Binding the Strong Man. A political Reading of Mark's Story of Jesus (Maryknoll, NY: Orbis Books 1988) 240. Quanto a Betsaida, resta il problema che in Mc questo luogo viene chiamato villaggio $(8,23.26)$, malgrado gli altri testi del Nuovo Testamento la chiamino città (Mt 11,20; Gv 1,44). I dati storici, come già abbiamo visto, ci informano che Betsaida è stata elevata a città. Fra gli esegeti ci sono opinioni diverse sul perchè Marco tratti questa città come un villaggio. La prima spiegazione è che si tratti di un errore di Marco dovuto alla sua scarsa conoscenza della geografia, oppure villaggio è detto in dizione popolare (vedi per es. J. Ernst, Il Vangelo secondo Marco [Brescia: Morcelliana 1991] 361; anche: E.S. Johnson, "Mark VIII.22-26: The Blind Man from Bethsaida", NTS 25 [1978/1979] 371-372). Un'altra proposta colloca la guarigione del cieco non a Betsaida stessa ma in un villaggio situato nelle vicinanze (K. Stock, Marco. Commento contestuale al secondo Vangelo [Roma: Apostolato della Preghiera 2003] 148). Una terza possibilità dice che "malgrado l'ampliamento per opera del tetrarca Filippo e il cambiamento di nome in Julia, Betsaida giuridicamente rimaneva un villaggio anche come capoluogo della Gaulanitide" (J. Gnilka, Marco [Assisi: Cittadella 1987] 434; cfr. Malina, Ewangelia, 464). Potrebbe essere anche come suggerisce Guelich sulla base dell'esegesi di Bultmann, vale a dire che, all'inizio, il racconto della guarigione del cieco esisteva indipendentemente ed era collocato in "un villaggio" non meglio precisato. Nella seconda tappa, 
Riassumendo, è importante sottolineare che all'inizio del nostro brano i discepoli raggiungono lo scopo già menzionato in Mc 6,45 e raggiungono un luogo strettamente collegato con la potenza miracolosa di Gesù.

\section{b) La presentazione di un cieco e la richiesta di guarigione (Mc 8,22b).}

Il cieco non si presenta da solo, sono gli altri a condurlo a Gesù. Il verbo $\phi \epsilon ́ \rho \omega$ che significa "portare", "recare", "condurre", ricorre spesso in Mc, nei racconti di guarigioni miracolose. I malati non sono autosufficienti, ma devono essere condotti a Gesù. Così succede in Mc 1,32 dove si dice in modo generico: "

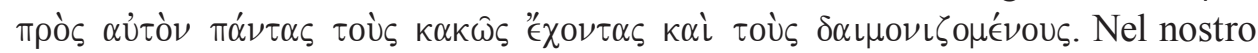
brano, non si comprende chi fossero esattamente le persone che hanno portato il cieco a Gesù. Potevano essere i discepoli (una presenza difficile da decifrare nel nostro racconto) ma essi non erano quasi mai i promotori delle iniziative dei miracoli operati da Gesù. Identificare queste persone con la folla (che nel racconto di Mc 10,46-52 è presente accanto ai discepoli di Gesù) è più plausibile, ma sembra d'altra parte qualcosa di molto generico. Più probabile è la loro identificazione con degli amici del cieco che lo aiutavano. Sono persone che conoscono la malattia e il dramma del non-vedente, ma anche persone che sicuramente dovevano conoscere Gesù. La loro presenza ha una valenza funzionale e costruisce un ponte tra il cieco e Gesù-taumaturgo ${ }^{20}$.

Il verbo фé $\rho \omega$ viene usato in Mc 2,3 nel suo significato fondamentale: "portare" (un paralitico portato da quattro persone); lo troviamo anche in $\mathrm{Mc}$ 7,32 (guarigione di un sordomuto) e Mc 9,17.19.20 (l'epilettico indemoniato) ${ }^{21}$.

l'evangelista Marco avrebbe usato questo racconto nel suo Vangelo, aggiungendo il versetto introduttivo e redazionale (v. 22) con la collocazione a Betsaida (Guelich, Mark 1-8:26, 432).

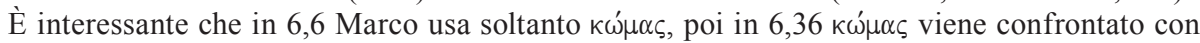

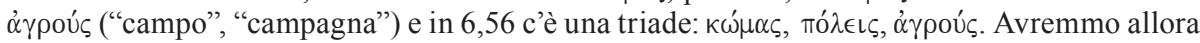
una distinzione basata probabilmente sulla grandezza indicata da queste espressioni: пó $\lambda\llcorner\varsigma$

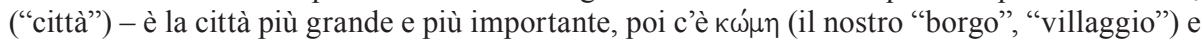

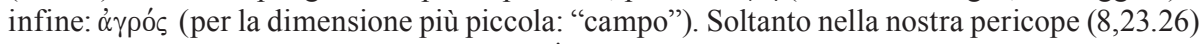
e prima di entrare a Gerusalemme $(11,2) \kappa \omega ́ \mu \eta$ viene usato al singolare. Così come in Mc 11,2, Gesù parla di un villaggio vicino alla città di Gerusalemme anche nel nostro versetto $(8,23 \mathrm{e}$ poi 8,26$)-\kappa \omega ́ \mu \eta$ si potrebbe riferire non a Betsaida ma ad una borgata. Sembra che questo sia il significato preferito da Gianattilio il quale scrive: "Per cercare coerenza nelle parole di Marco si può ipotizzare il riferimento non propriamente alla città, ma ad un piccolo borgo periferico che ne assumeva genericamente la designazione" (Gianattilio, Personaggi minori, 224).

Come già abbiamo visto nella critica testuale, alcuni manoscritti, probabilmente a causa del fatto che la "città" viene chiamata un "villaggio", hanno cambiato il nome Betsaida in Betania, probabilmente la stessa città di cui si parla in Gv 1,28 (cfr. Ernst, Il Vangelo, 361).

20 Vedi: E. Salvatore, E vedeva a distanza ogni cosa. Il racconto della guarigione del cieco di Betsaida (Mc 8,22-26) (Roma-Brescia: Editrice Pontificia Università Gregoriana 2003) 71-73.

21 In altri contesti ricorre il verbo фé $\rho \omega$ : in Mc 4,8 (un grano che sulla terra buona porta frutto); 6,27-28 (il martirio di Giovanni il Battista); 11,2.7 (i discepoli portano un asino prima 


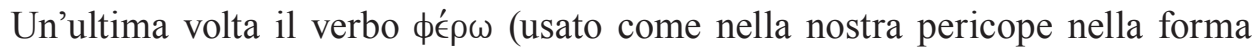
dell'indicativo presente attivo della terza persona plurale) viene usato nella parte

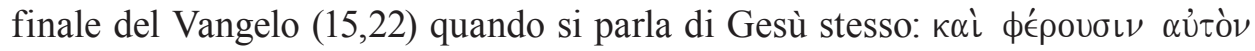

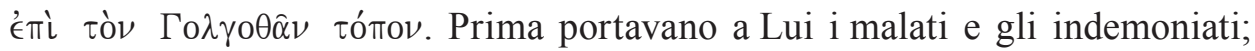
adesso è Gesù stesso ad esser condotto al luogo del Golgota. In entrambi i casi $(8,22 \mathrm{~b}$ e 15,22$)$, il soggetto del verbo è sconosciuto. In $8,22 \mathrm{~b}$ sembrano essere gli uomini oppure gli amici del cieco - probabilmente gli stessi che sono stati visti da lui come alberi - dopo la guarigione parziale (v. 24) ${ }^{22}$. In 15,22 sono usate come soggetto anche le persone in generale, ma sicuramente esse non erano gli

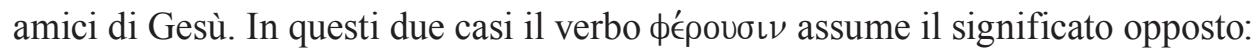
"condurre per guarire", oppure: "condurre per uccidere".

Nel Vangelo di Marco ci sono soltanto due scene in cui si parla di un cieco

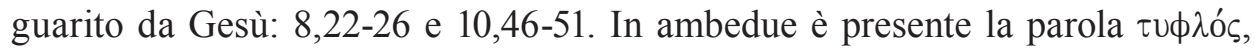
usata di solito come sostantivo. Soltanto in 10,46 ricorre nell'uso aggettivale

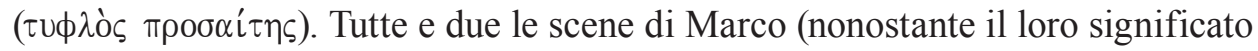
simbolico) si riferiscono alle persone malate fisicamente ${ }^{23}$.

La presentazione dei malati nel linguaggio marciano è diverso. Si parla di malati collettivi che ritroviamo nei sommari $(1,32)$ oppure di persone presentate singolarmente, ma in modo anonimo. Questa seconda categoria viene caratterizzata soltanto attraverso il tipo di malattia (così abbiamo un uomo posseduto da uno spirito immondo in 1,23, un lebbroso in 1,40, un paralitico in 2,3 etc.). Il terzo gruppo - il più piccolo di tutti - è costituito dai malati con il nome proprio (abbiamo soltanto Bartimeo in 10,46, non dimenticando che il suo nome significa etimologicamente solo "figlio di Timeo") oppure identificati come membri di una certa famiglia (la suocera di Simone in 1,30; la figlia di Giàiro in 5,23). Il cieco del nostro racconto, rientrando nel secondo gruppo di malati, rimane anonimo. Entra in scena all'improvviso. Non conosciamo neanche il suo nome. L'assenza del nome "non è un fatto casuale ma un'omissione ben calcolata. Quest'uomo che per la sua malattia non vede [...], è pertanto un personaggio che anche il lettore fa fatica a vedere [...]. Egli non vede, ma il lettore, metaforicamente parlando, non vede bene chi è lui" ${ }^{24}$. L'unica caratteristica del cieco è proprio quella che non poteva vedere.

dell'ingresso di Gesù in Gerusalemme); 12,15-16 (si parla del tributo a Cesare e di una moneta che viene portata a Gesù).

22 Gundry, Mark, 417.

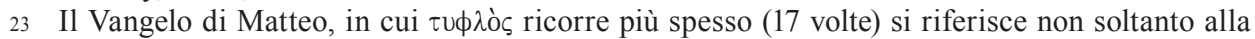
cecità fisica (Mt 9,27.28; 11,5; 12,22; 15,14.30.31; 20,30;21,14) ma anche alla malattia spirituale (Mt 15,14; 23,16.17.19.24.26), riferita anche ai farisei (Mt 23,26); la stessa differenza si trova anche in Lc (cecità fisica: 4,18; 7,21.22; 14,13.21.35; cecità spirituale: Lc 6,39).

24 Salvatore, E vedeva, 73. 
Gli uomini non soltanto portano un cieco a Gesù ma si rivolgono anche a lui pregandolo di toccarlo. La loro richiesta viene espressa con il verbo $\pi \alpha \rho \alpha \kappa \hat{\alpha}$ $\lambda \lambda^{\prime} \omega$ che significa pregare, invitare, esortare, consolare ${ }^{25}$. Matteo e Luca lo usano ogni tanto in relazione con "la consolazione del tempo finale [...], che consiste nell'annuncio dell'azione di Dio: Beati gli aflitti, perchè saranno consolati o dall'intervento di Dio a loro favore (Mt 5,4), o mediante il superamento dei mali di questo mondo (Lc 16,25)"

Le persone che conducono il cieco si rivolgono personalmente a Gesù suppli-

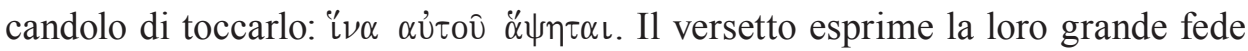
nella potenza di Gesù, collegata con un'umile supplica. Il verbo پ̋ $\pi \omega$, che nel Vangelo di Marco ricorre ben 11 volte, si riferisce quasi sempre ad un miracolo di guarigione (l'unica eccezione è 10,13). I soggetti di questo verbo si possono dividere in due gruppi: 1) Gesù che tocca il malato (come succede nella guarigione del lebbroso: 1,41; del sordomuto: 7,33); 2) i malati che toccano Gesù (le folle: 3,$10 ; 6,56$; una donna affetta da emorragia: 5,27.28.30.31); particolarmente nel cap. 5 si sottolinea il tocco particolare da parte della donna. Nel nostro caso $(8,22)$, sembra che il soggetto del verbo $\alpha$ $\psi \eta \tau \alpha \iota$ sia Gesù. Comunque questa non è l'unica possibilità. Anche il cieco potrebbe essere il soggetto di "toccare". Questa possibilità deriva dal fatto che Gesù non è stato menzionato esplicitamente nella nostra frase. Anche i motivi fonetici agiscono a vantaggio del cieco: Kai

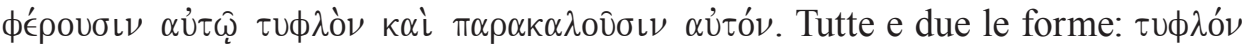
e $\alpha$ ¿óv sono all'accusativo. Allora nel nostro versetto si potrebbe intravedere anche la possibilità che gli amici del cieco lo portano a Gesù e poi lo (cioè il cieco) esortano (un altro significato del verbo $\pi \alpha \rho \alpha \kappa \alpha \lambda^{\prime} \epsilon \omega$ ) a toccare Gesù2 ${ }^{27}$.

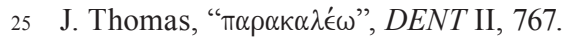

26 Thomas, "п $\alpha \rho \alpha \kappa \alpha \lambda \epsilon ́ \omega ", D E N T$ II, 771. Nel Vangelo di Marco questo verbo è presente quattro volte nella pericope che parla dell'indemoniato geraseno: il demonio scongiura Gesù affinché non lo cacci fuori del paese $(5,10)$ e poi affinchè lo mandi dai porci $(5,12)$; gli abitanti di quella regione pregano Gesù di andare dal loro territorio $(5,17)$; alla fine l'indemoniato guarito prega che gli sia consentito di stare con Gesù $(5,18)$. Tutti gli altri cinque casi si riferiscono a guarigioni di malati: il lebbroso che in ginocchio supplica Gesù $(1,40)$, Giàiro che gli si gettò ai piedi e lo pregava con insistenza $(5,22 \mathrm{~b}-23 \mathrm{a})$, i malati nel paese di Genèsaret $(6,56)$, le persone che conducono un sordomuto $(7,32)$ e gli uomini che portano il nostro cieco $(8,22)$. Il nostro versetto $(8,22)$ è proprio l'ultimo del Vangelo di Marco in cui è usato il verbo $\pi \alpha \rho \alpha \kappa \alpha \lambda \lambda^{\prime} \omega$.

27 Un'osservazione interessante viene anche dall'analisi del verbo $\ddot{\pi} \pi \omega$ usato nelle due forme: indicativo aoristo medio (Mc 1,41; 5,27.30.31; 6,56b; 7,33) e congiuntivo aoristo medio (Mc 3,10; 5,28; 6,56; 8,22; $10,13)$. Il verbo, quand'è usato al congiuntivo, ha quasi sempre (ad eccezione di 10,13) come soggetto una persona malata (questo agisce a vantaggio del cieco come soggetto del "toccare" nel nostro versetto). Tuttavia in Mc 10,13 il soggetto del congiuntivo aoristo medio è chiaramente Gesù. Inoltre, tutti e due i versetti presentano una somiglianza:

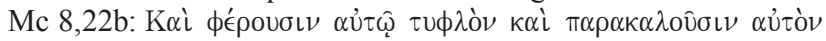

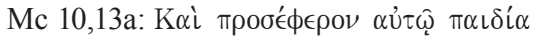

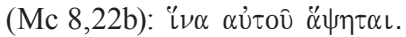

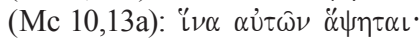




\subsection{Il centro del racconto - la descrizione della cura $(8,23-25)$}

La parte centrale del racconto descrive la cura: si comincia con l'allontanamento dal villaggio (v. 23a) e con i primi gesti terapeutici di Gesù (v. 23b). La guarigione, che prima è ancora insufficiente (v. 24), dopo la seconda imposizione delle mani di Gesù (v. 25a), porta il cieco al ristabilimento completo della vista (v. 25b).

\section{a) Allontanamento dal villaggio (v. 23a)}

Il primo gesto di Gesù è di prendere il cieco per mano. L’espressione: é $\pi\llcorner\lambda \alpha \beta o ́ \mu \in \nu \circ \varsigma$

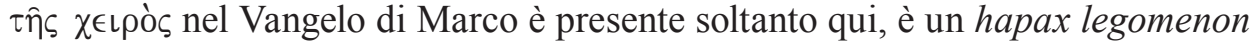
marciano. Anche Matteo usa il verbo ém $\iota \lambda \alpha \mu \beta \alpha_{\alpha} \nu \rho \mu \alpha \iota$ soltanto una volta $(14,31)$. Luca invece lo usa più spesso: cinque volte nel suo Vangelo e sette volte negli Atti. Ma il contesto nel quale viene usato da Luca è di solito diverso dalla guarigione $^{28}$. Soltanto in Lc 14,4 Gesù prese un idropico per guarirlo. "Prendere per mano" si trova soltanto in At 23,19, ma vi è usato in senso più generale - il tribuno prese per mano il figlio della sorella di Paolo e lo condusse in disparte per conoscere le parole che il ragazzo ha portato da Paolo imprigionato. Nel contesto più ampio dell'imprigionamento di Paolo, poi, "prendere per mano" (At 23,19) significa "voler aiutare Paolo"29. Prendendo il significato dell'espressione

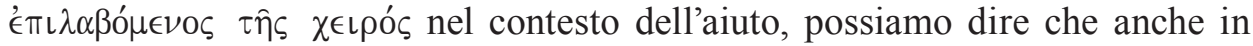
Mc 8,23a gli si può attribuire lo stesso valore: Gesù "prende per mano" il cieco per aiutarlo ${ }^{30}$. Questo gesto di Gesù si può spiegare in modo molto semplice: l'uomo cieco non poteva seguire Gesù da solo; così Gesù, se voleva condurlo fuori di Betsaida, doveva prenderlo per mano ${ }^{31}$. Con questo gesto, Gesù riprende l'azione degli uomini che gli hanno portato il cieco, "conducendo il cieco per mano assume la consegna che gli aiutanti gli avevano dato; accetta l'impegno a farlo ritornare vedente" ${ }^{\text {"32 }}$.

La prossimità del verbo al participio aoristo $\left({ }^{\epsilon} \xi \eta \dot{\eta} \nu \in \gamma \kappa \in \nu\right)$, con chiaro valore temporale del passato, ci dà anche la possibilità di tradurre il participio aoristo

Entrambi parlano di uomini (non meglio identificati) che portano altri (un cieco, i bambini) perchè Gesù li tocchi. Anche nel racconto della guarigione di un sordomuto (Mc 7,31-37) che, come vedremo dopo, presenta tante somiglianze con il nostro brano, il soggetto di toccare è Gesù.

28 Vedi per es. Lc 9,47; 20,20.26; 23,26; At 9,27; 16,19; 17,19; 18,17; 21,30.33.

29 La frase in At 23,19 presenta una certa somiglianza con Mc 8,23a:

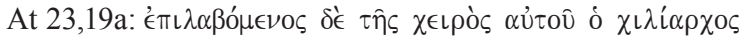

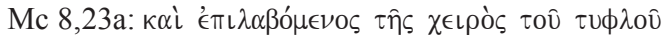

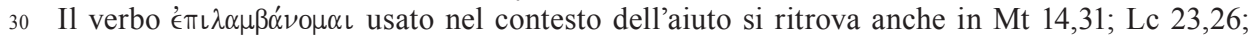

At 9,27.

31 Gundry, Mark, 417.

32 Salvatore, E vedeva, 61. 
$€ \pi \iota \lambda \alpha \mu \beta \alpha \dot{\alpha} \nu 0 \mu \alpha \iota$ come: dopo aver preso il cieco per mano ${ }^{33}$. Gesù, preso il cieco per mano, lo condusse fuori dal villaggio. Condusse fuori è la seconda azione

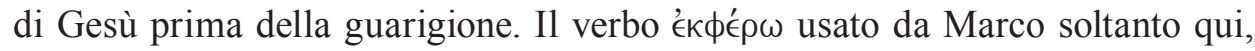
non viene usato neanche una volta da Matteo. Luca lo usa in 15,22, ma in un contesto diverso. È interessante osservare che questo verbo viene usato quattro volte negli Atti, ma tutte nel solo cap. 5 . Tre volte $(5,6.9 .10)$ "portare fuori" si riferisce alle salme di Anania e Saffira dopo la loro frode ("portare fuori" per seppellire); una volta $(5,15)$ è usato proprio con riferimento ai malati che venivano portati fuori nelle piazze quando passava Pietro: qui chiaramente é $\kappa \phi \epsilon ́ \rho \omega$ è usato nel contesto della guarigione.

Nel nostro versetto, il gesto di Gesù diventa un po' misterioso. Ci sono diverse spiegazioni di questa conduzione fuori dal villaggio. Per alcuni, essa equivale a una "caratterizzazione di mago o operatore di cose prodigiose che non possono essere divulgate" ${ }^{34}$. Altri esegeti invece giustificano la conduzione fuori dal villaggio a causa della "particolarità della malattia [...], motivo redazionale del segreto, oppure l'ipotesi di una sfera intima per il miracolo" ${ }^{\text {35 }}$. Condurre fuori dal villaggio non significa tuttavia assenza assoluta delle altre persone. Il testo non dice niente dei discepoli di Gesù, vale a dire se essi restano nel villaggio oppure se vanno nsieme a Gesù e il cieco. Anzi, nel v. 24, dopo la prima tappa della cura, il cieco vede gli uomini come alberi che camminano; questa osservazione potrebbe suggerire che il miracolo è stato fatto non nell'isolamento assoluto, ma soltanto "fuori dal villaggio" ${ }^{36}$. Gesù vuole operare la sua guarigione senza le folle ed anche fuori da Betsaida che, come abbiamo già visto, era famosa sia per i miracoli, sia per la sua incredulità (cfr. Mt 11,21; Lc 10,13) ${ }^{37}$.

Alcuni studiosi, come per esempio Légasse ${ }^{38}$, analizzando il nostro brano, vi ritrovano un riferimento al testo di Geremia. Infatti mettendo a confronto tutti e due i testi greci (il testo di Geremia preso dai LXX dal cap. 38 che nel testo ebraico si trova nel cap. 31) possiamo cogliervi subito una somiglianza:

33 Nella guarigione del cieco Marco separa queste due azioni: "prendere per mano" e "condurre fuori". Nel racconto della guarigione del sordomuto (Mc 7,31-37) che assomiglia al nostro

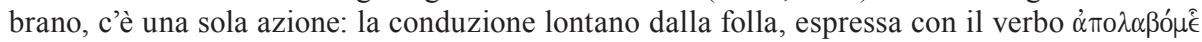

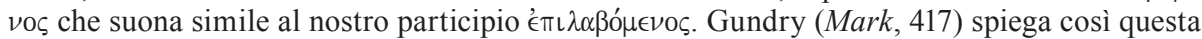
somiglianza: "At 7:33 Mark used $\alpha \pi \operatorname{\pi } \lambda \alpha \beta$ ó $\mu \in \nu \circ \varsigma$ for the taking aside. Now the prefix changes to $\epsilon \pi \iota$ - because Jesus must lay hold on the blind man's hand to lead him aside". Salvatore, E vedeva, 61 .

Ernst, Il Vangelo, 361.

Vedi: Guelich, Mark 1-8:26, 432.

Cfr. J.R. Edwards, The Gospel according to Marc (Grand Rapids, MI - Cambridge, UK: Eerdmans 2002) 242

38 Légasse, Marco, 411. 


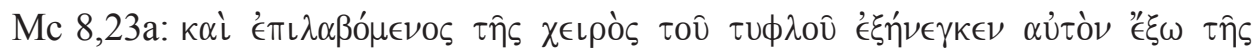
$\kappa \omega \dot{\mu \eta} \varsigma$

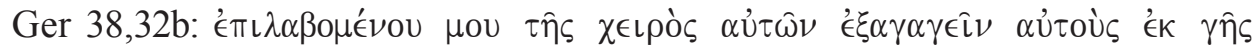
Aìútrou

Il testo di Ger 38,32b evoca l'uscita dall'Egitto quando Dio prende per mano il suo popolo e lo fa uscire dalla schiavitù egiziana. Come osserva Légasse: "la somiglianza tra i due testi è tale che non si può escludere l'idea di un simbolismo" ${ }^{39}$. Come Dio ha fatto uscire il suo popolo dall'Egitto, così Gesù conduce ora il cieco fuori dal villaggio. Né in Egitto né a Betsaida il popolo crede ai miracoli fatti da Dio. Gesù vuole perciò operare la guarigione al di fuori del posto in cui la gente, anche se avesse veduto il miracolo, non avrebbe creduto in Gesù.

\section{b) I gesti terapeutici di Gesù}

Gesù opera il suo miracolo con due gesti terapeutici: inizia con lo sputare sugli occhi del cieco e poi impone le mani al malato.

Nel Nuovo Testamento, oltre al nostro brano, il verbo $\pi \tau v$ $\omega$ che significa "sputare" ricorre soltanto tre volte: in Mc 7,33 (in un testo molto simile al racconto della guarigione del nostro cieco) Gesù tocca con la saliva la lingua del sordomuto; in Gv 9,6 fa del fango con la saliva e poi lo spalma sugli occhi del cieco. Nell'antichità giudaica, la saliva era riconosciuta come rimedio, in particolare per gli occhi ${ }^{40}$ : possedeva la forza di cacciare il demonio della malattia ${ }^{41}$, perciò si collegava spesso alla recitazione delle formule magiche. Gesù non le recita, ma impone le mani al malato. Il tocco con la saliva non era sconosciuto nemmeno nel mondo ellenistico. Tacito, per esempio, nelle Historiae, descrive un episodio della vita di Vespasiano (imperatore romano che ha regnato dal 69 al 79 d.C.) che ad Alessandria guarì un cieco bagnandogli gli occhi con la sua saliva ${ }^{42}$. Gesù usa questo segno della saliva, conosciuta nell'antichità, per mostrare al cieco che la guarigione sta proprio per arrivare ${ }^{43}$. I segni visibili solo con gli occhi non bastano per chi non vede. Il cieco ha bisogno di essere

39 Légasse, Marco, 411.

40 Lègasse, Marco, 412. Vedi anche K. Gerber Ayayo, "Magical Expectations and the Two-Stage Healing of Mark 8", Bulletin for Biblical Research 24.3 (2014) 385-386.

41 Cfr. Gnilka, Marco, 434. J.D.M. Derrett ("Trees Walking, Prophecy, and Christology”, Studia Theologica 35 [1981] 39) vede nel segno della saliva "a folk-method of dispelling evil or insulating oneself from a demon".

42 Tacito, Historiae IV.81 (da leggere anche in: http://www.progettovidio.it/dettagli1.asp?id=1855 \&opera $=$ Storie\&libro=Libro\%20IV). Per leggere la storia con un commento vedi: Eckey, Das Markusevangelium, 220-221. La storia paragonata con le descrizioni di Svetonio e Cassio Dione in E. Eve, "Spit in Your Eye: The Blind Man of Bethsaida and the Blind Man of Alexandria", NTS 54 (2008) 2-12.

43 Moloney, The Gospel, 164. 
toccato; perciò Gesù lo prende per mano, sputa sui suoi occhi e gli impone le mani $^{44}$. Il contatto fisico è necessario.

Nel racconto della guarigione vengono usati due termini diversi per gli occhi. Nel v. 25 è usato il termine più normale, ỏ $\phi \alpha \alpha \lambda \mu$ ós, che ricorre cento volte nel Nuovo Testamento. Nel nostro versetto invece viene usata la parola ő $\mu \mu \alpha$. Possiamo trovarla soltanto qui ed anche in Mt 20,34, nel racconto della guarigione dei due ciechi di Gerico. In tutte e due i casi la parola ő $\mu \alpha$ si riferisce agli occhi dei ciechi. Nei commentari viene spiegata come un termine più poetico ${ }^{45}$.

Il termine ő $\mu \alpha \alpha$ occorre più spesso nei LXX, in cui possiamo trovarlo come traduzione dell' ebraico עין; e viene usato non soltanto in riferimento all'occhio come membro del corpo, ma anche con un significato metaforico. Per esempio in Prov 7,2b leggiamo: il mio insegnamento sia come la pupilla dei tuoi occhi

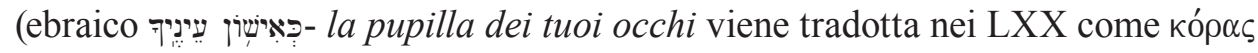
ó $\mu \mu \alpha \dot{\tau} \omega \nu)$, dove il nostro termine assume certamente un senso metaforico. Come metafora ő $\mu \alpha \alpha$ ricorre anche molto spesso nei testi classici della letteratura greca ${ }^{46}$. L'abitudine di usare la saliva e di sputare sugli occhi possono avere nella nostra pericope non soltanto il significato letterale ma anche uno più profondo - metaforico. Gesù guarisce non soltanto gli occhi del corpo ma anche "gli occhi" dello spirito.

Il secondo gesto terapeutico di Gesù è l'imposizione delle mani, cioè la risposta immediata alla preghiera degli amici che gli hanno portato il cieco pregando di toccarlo. Il verbo usato nella locuzione stereotipica "imporre le

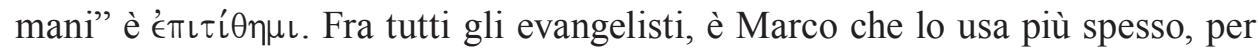
otto volte. Il verbo viene usato da Marco in due contesti: il primo si riferisce al cambiamento del nome di un discepolo (3,16-17), il secondo invece appartiene ad una scena di guarigione, quando si parla dell'imposizione delle mani come di un gesto terapeutico ${ }^{47}$. È interessante notare che dopo il cap. 3 (cioè dopo

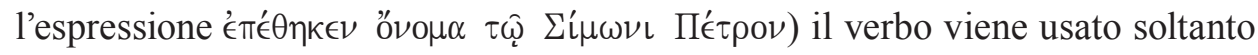
nel contesto della guarigione. Non possiamo escludere che, come il cambiamento del nome cambia l'identità di un personaggio, così anche l'imposizione delle mani durante la guarigione ha lo stesso effetto. La persona che è stata guarita riceve così una nuova identità, una vita nuova ${ }^{48}$.

44 Lo sputo direttamente sugli occhi del cieco viene spiegato da Gundry (Mark, 417): "at 7:33 Jesus spat on his own fingers and touched the deaf mute's tongue. Now Jesus spats directly into the blind man's eye because they are exposed as the deaf mute's tongue was not".

45 France, The Gospel, 324. C'è anche la possibilità che l'usanza della lingua più arcaica insieme con il simbolo della saliva potrebbero suggerire il rito più formale della guarigione (vedi France, The Gospel, 324).

46 Johnson, The Blind Man, 375.

47 Mc 5,23; 6,5; 7,32; 8,23.25; 16,18.

48 Il cambiamento della propria identità dopo il gesto dell'imposizione delle mani è visibile anł che nel contesto dell'ordinazione sacerdotale. In At 6,6 con tale gesto vengono istituiti i sette 
Il gesto dell'imposizione delle mani era conosciuto già nell'Antico Testamento. Possiamo trovarlo in quattro contesti: a) l'offerta del sacrificio a Dio (Es 29,10.15; Lv 1,4;3,2), b) la consacrazione dei leviti (Num 8,10) che era interpretata anche nel contesto dell'offerta fatta a Dio (in Num 8,11 troviamo una prescrizione che dice che Aronne presenterà i leviti come offerta [...] da parte degli Israeliti), c) la benedizione dei figli e del popolo da parte dei patriarchi e dei sacerdoti (Gen 48,14; Lv 9,22; Sir 50,20), d) la guarigione, ma in questo contesto l'imposizione delle mani ricorre soltanto una volta $(2 \mathrm{Re} 5,11)$ e soltanto come una speranza vuota di Nàaman. Considerando tutti e quattro i contesti, vediamo che l'imposizione delle mani era, nella maggior parte dei casi, collegata con un sacrificio fatto a Dio oppure con la benedizione. In entrambi i casi, il fine era lo stesso: trasformare un animale oppure una persona dallo stato profano allo stato sacro, dedicato a Dio. Come spiega Edwards, quando Gesù impone le mani sulla persona, l'effetto è piuttosto l'opposto: il profano non viene più elevato ad essere sacro. Gesù mostra la presenza guaritrice di Dio alle persone ordinarie, comuni, anche alle peccatrici. Gesù porta il sacro (la forza guaritrice, la grazia di Dio) al profano ${ }^{49}$. Anche nel nostro brano, Gesù porta la guarigione ad un cieco senza condizioni particolari; non chiede della sua fede, vuole soltanto aiutarlo. Non sappiamo la storia del cieco né prima, né dopo la guarigione; gli effetti spirituali sono sconosciuti.

Nel rapporto medico - paziente (nella nostra scena: guaritore - ammalato) il contatto fisico, il tocco è necessario; può essere anche visto come gesto rassicurante, particolarmente per una persona che non vede. L'imposizione delle mani resta però il vero gesto risanante, così come in Mc 7,33 il tocco delle orecchie con le dita. Il primo gesto di Gesù - lo sputo - appare in questo contesto solo come una preparazione al miracolo ${ }^{50}$.

Dopo questi due gesti terapeutici, Gesù, per la prima volta nella nostra pericope, comincia a parlare e si rivolge al cieco con una domanda: $\epsilon^{\prime \prime} \tau \iota \beta \lambda \lambda^{\prime} \in \operatorname{\epsilon \iota } \iota$; Il

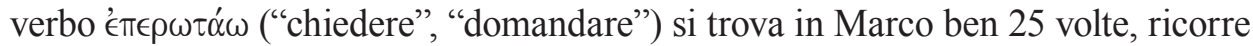

diaconi. Anche nelle lettere pastorali il senso di '́đ $\iota \theta \epsilon i \zeta$ è liturgico. L'imposizione delle mani del collegio dei presbiteri è compiuta per comunicare il $\chi \alpha ́ \rho\llcorner\sigma \mu \alpha(1 \mathrm{Tm} 4,14 ; 5,22 ; 2 \mathrm{Tm} 1,6)$.

49 Edwards, The Gospel, 243.

50 Gnilka, Marco, 434. Gerber Ayayo vede una grande opposizione tra questi due gesti di Gesù. Il primo momento - lo sputo, risulta insufficiente come insufficienti lo erano i gesti magici dei vari taumaturghi dell' epoca. Il secondo - l'imposizione delle mani, è caratteristico soltanto di Gesù e sottolinea la sua forza divina: "Thus, the account of a successful healing in Mark $8: 25$ by means of Jesus' touch stands in stark contrast to the insufficient results produced by the prior method that was consistent with magical practices. The implication is that any who classify Jesus in the category of magician must reconsider who he is" (Gerber Ayayo, "Magical Expectations", 391). 
cioè con particolare frequenza ${ }^{51}$. Per otto volte in $\mathrm{Mc}$ è Gesù che domanda ${ }^{52}$; ma domandano anche i suoi discepoli ${ }^{53}$ oppure le altre persone ${ }^{54}$. Analizzando i versetti in cui si trova il verbo $\epsilon \pi \epsilon \rho \omega \tau \alpha^{\prime} \omega$ si può vedere che quando viene usato dai discepoli oppure da altre persone, ciò avviene perché chi domanda vuol

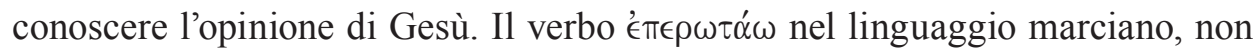
significa dunque semplicemente: domandare, ma piuttosto: chiedere per conoscere l'opinione di un'altra persona (di Gesù). Anche Gesù lo usa spesso in questo significato. Come osserva Schenk, "il verbo indica sul piano metalinguistico un'azione verbale costituita da una sola frase, che richiede a chi è interpellato di dare un'informazione, o di prendere una decisione, o di esprimere una conferma riguardo ad una determinata situazione di fatto [...]. La funzione narrativa del dialogo tra persone è per Mc un importante mezzo stilistico per introdurre in contesti narrativi considerazioni valutative" ${ }^{\prime 5}$.

Gesù rivolge una domanda al cieco per sapere che cosa lui può vedere. Si comporta "proprio come un medico che interroga il suo paziente per vedere gli effetti della terapia" ${ }^{56}$. È l'unico caso in tutte le guarigioni del Vangelo. Gesù non aveva mai fatto domande riguardo agli effetti dei suoi miracoli. Come osserva Salvatore, "la storia della guarigione dopo l'imposizione delle mani richiederebbe come suo naturale epilogo la formula conclusiva della riacquisizione della salute. E invece ecco una variazione imprevista" ${ }^{57}$. Gesù non può non essere sicuro dell'effetto del suo trattamento. La domanda significa da una

51 In Mt solo 8 volte, in Lc 17 volte e in Gv soltanto 2 volte.

52 Gesù parla nel contesto della cacciata del demonio: Mc 5,9; della guarigione: Mc 8,23; 9,21 ed anche per conoscere l'opinione degli altri: Mc 8,27.29; 9,16.33; 11,29).

53 I discepoli domandano il significato della parabola: Mc 7,17; sull'insegnamento degli scribi: Mc 9,11; quando non possono scacciare un demonio: Mc 9,28; sul divorzio: Mc 10,10; una volta sono soltanto i tre apostoli: Pietro, Giovanni e Giacomo- a chiedere degli eventi escatologici: Mc 13,3; una volta Mc dice che i discepoli avevano timore di chiedergli spiegazione (Mc 9,32).

54 Gli altri che domandano sono: i farisei, sadducei e gli scribi (Mc 7,5; 10,2; 12,18.28), un giovane (Mc 10,17), le persone anonime, descritte come "tutti" (Mc 12,34), il sommo sacerdote (Mc 14,60-61) ed alla fine Pilato (Mc 15,2.4.44).

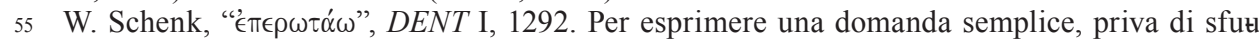
matura valutativa, Marco usa un altro verbo, più semplice: ' $€ \omega \omega \tau \alpha$ c $\omega$. Nel linguaggio di Gesù lo

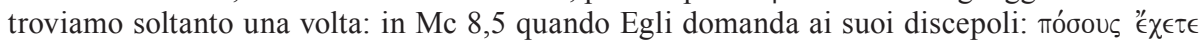

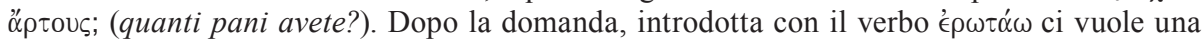
risposta breve, semplice e concreta, non l'opinione di alcuno (Vedi Schenk, "' $\rho \omega \tau \alpha \dot{\alpha} \omega$ ", DENT I, 1392-1394).

56 Salvatore, E vedeva, 68. Derret vede nella domanda di Gesù un riferimento alle domande rivolte da Dio ai profeti. Suggerisce anche di riferire la domanda: "che cosa vedi?" a tutto ciò che deve accadere nel futuro: "The question was put twice to Jeremiah: 'What do you see?' (Jer 1:11-13), and each time the thing seen [...] was a symbol of things to come [...], a siege that the Lord was preparing for Jerusalem and 'all the cities of Judah'[...]! At Nah 2:3-5 the prophet 'sees' the war and the siege actually in progress" (Derrett, "Trees Walking", 40).

57 Salvatore, E vedeva, 68. 
parte che la guarigione non è ancora finita ${ }^{58}$ e dall'altra che Gesù vuol indurre il cieco a riflettere su che cosa può effettivamente vedere, su qual è lo stato della

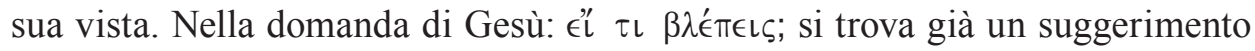
della risposta. Il pronome indefinito $\tau \iota$ prepara, già nella domanda di Gesù, la risposta del cieco. Tı come "qualcosa" 59 viene ripreso poi nel senso delle parole del malato: lui non vede ancora bene, cioè vede "qualcosa". Non tutto è ancora chiaro per lui.

\section{c) Dichiarazione della guarigione insufficiente (v. 24)}

I due gesti terapeutici di Gesù: lo sputare e l'imposizione delle mani che terminano con la domanda sul risultato di tale guarigione, provocano una risposta da parte del cieco. Prima di dire qualcosa, lui alzò gli occhi. Nell'Antico Testamento (nei LXX) il verbo $\dot{\alpha} \nu \alpha \beta \lambda \epsilon \in \omega \omega$ viene usato per rendere diverse parole ebraiche: ראה , פנה , ערג, ,נשא, נבט, אור esso può avere di norma tre significati diversi: a) alzare gli occhi (per es. Gen 13,14), b) guardare in cielo (per es. Gen 15,5), c) recuperare la vista (Is 42,18; Tob 11,8; 14,2). Nel nostro contesto risulta più importante proprio questo terzo significato che può essere trovato anche nella letteratura greca ${ }^{60}$. Il verbo $\dot{\alpha} \nu \alpha \beta \lambda \epsilon \epsilon \omega$ occorre, nel Nuovo Testamento ben 25 volte e può avere significati diversi, collegati con il senso di vedere. Può indicare una semplice percezione ottica (per es. Gesù alza gli occhi per vedere Zaccheo che era salito su un sicomoro in Lc 19,5); un alzare gli occhi al cielo come atto di speranza in Dio (per es. prima della moltiplicazione dei pani in Mc 6,41 oppure nel racconto della guarigione del sordomuto in Mc 7,34); il riacquistare la luce degli occhi (come in Mc 10,51 dove un cieco chiede: Rabbunì, che io riabbia la $v i s t a-i \nu \alpha \alpha \dot{\alpha} \nu \alpha \beta \lambda \epsilon^{\epsilon} \psi \omega$, e poi nel versetto seguente: subito riacquistò la vista -

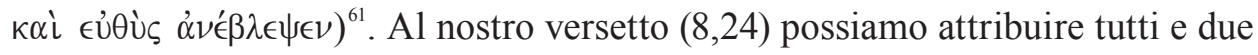
i significati: il cieco alzò gli occhi oppure il cieco riacquistò la vista. Tuttavia siccome in Mc 10,51-52 $\alpha \nu \alpha \beta \lambda \epsilon ́ \pi \omega$ significa "riacquistare la vista", nel nostro versetto (in cui il cieco non poteva ancora vedere bene) sembra più probabile il significato che si riferisce all'alzare gli occhi ${ }^{62}$. È probabile che Marco usi

58 Eckey, Das Markusevangelium, 220.

59 Gundry, Mark, 417.

60 Per spiegazioni più dettagliate vedi Johnson, The Blind Man, 376-377.

61 Vedi P.G. Müller, “¿ $\nu \alpha \beta \lambda \dot{\epsilon} \pi \omega ”, ~ D E N T$ I, 199-201.

62 Concorda con noi Ernst (Il vangelo, 362), che scrive "l'uomo solleva lo sguardo verso Gesù". La stessa opinione è condivisa anche da Salvatore (E vedeva, 75). Un'opinione diversa è invece quella presentata per esempio da Gundry (Mark, 417) il quale propende per il significato di $\alpha \nu \alpha \beta \lambda \epsilon ́\} \alpha \varsigma$ come "receiving sight [...] instead of looking up". Della stessa opinione sono Moloney (The Gospel, 164), il quale rende il verbo con "regained sight" e Guelich (Mark 1-8:26, 433). 
proprio questo verbo per rendere in una parola il doppio significato: il cieco ha alzato gli occhi e nello stesso tempo riacquistato la vista ${ }^{63}$.

Dopo la prima tappa della guarigione il cieco non poteva vedere chiaramente. Alla domanda di Gesù, il cieco risponde paragonando ad alberi gli uomini che camminavano. La prima parola della sua risposta è $\beta \lambda \epsilon^{\epsilon} \pi \omega$ e vien messa qua per enfatizzare il cambiamento della sua situazione. Prima era $\tau u \phi \lambda o ́ \varsigma$, adesso, dopo il primo contatto con Gesù, il cieco può dire: $\beta \lambda \epsilon ́ \pi \omega$. Il verbo significa: "vedere", "guardare", e viene usato nel senso "di una funzione fisico- ricettiva dell'occhio" " (così in Mc 13,2). Ma il significato di $\beta \lambda \lambda^{\prime} \pi \omega$ va spesso oltre la funzione fisica degli occhi e viene trasposto sul piano conoscitivo e acquista il senso traslato, metaforico di "guardare dentro", "scrutare", "rendersi conto di" ${ }^{65}$. Tante volte, nel Vangelo di Marco, $\beta \lambda \epsilon ́ \pi \omega$ viene usato in senso metaforico. Gesù usa spesso proprio questo verbo per rivolgersi ai suoi discepoli con un ammonimento: $\beta \lambda \lambda^{\prime} \pi \epsilon \tau \in(4,24 ; 8,15 ; 12,38)$. Interessante notare che la stessa forma ricorre cinque volte nel cap. 13, dedicato al discorso escatologico di Gesù (vv. 5.9.23.33). In tutti i casi summenzionati il verbo è all'imperativo. Nel nostro versetto, invece $(8,24)$, troviamo una forma all'indicativo, il che rende più probabile che essa sia usata nel senso semplice di vedere, tanto più che è usata nel contesto della guarigione di un cieco. Tuttavia non possiamo escludere neanche il senso traslato, e più profondo, del verbo vedere. Il cieco ci vede sì ma ancora in modo non chiaro, non riconosce ancora i contorni e non comprende bene la realtà che sta attorno a lui.

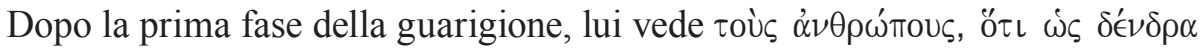

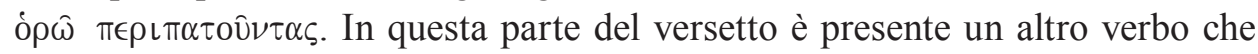
descrive la vista: ópó $\omega$. Nel Vangelo di Marco lo ritroviamo tante volte, riferito alla vista di Gesú ${ }^{66}$. Per la prima volta, ópów viene usato nella scena del battesimo

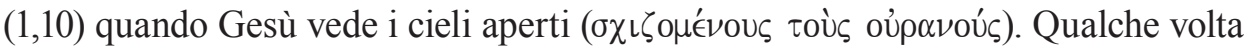
il verbo è usato anche nelle scene della vocazione dei discepoli $(1,16.19 ; 2,14)$. Talvolta questo verbo può significare la vista speciale degli uomini, collegata con la venuta finale di Gesù. Per due volte, poi, ópów è collegato con il vedere il Figlio dell'uomo alla fine dei tempi $(13,26 ; 14,62)$.

Nei capitoli finali di Mc (in cui si descrive la morte di Gesù sulla croce),questo verbo ricorre in stretto collegamento con la fede. Prima come una tentazione: Il Cristo, il re d'Israele, scenda ora dalla croce, perché vediamo e crediamo

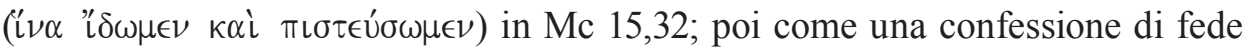

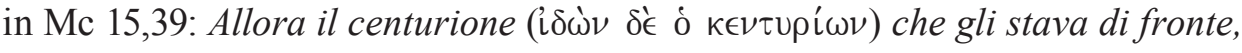

63 France, The Gospel, 325.

64 P.G. Müller, " $\beta \lambda \epsilon ́ \pi \omega ", D E N T$ I, 587.

65 Cfr. Müller, " $\beta \lambda \epsilon ́ \pi \omega ", 587$.

66 Per es. Mc 1,10.16.19; 2,5.14; 6,34.48; 9,25; 10,14; 11,13. 
vistolo spirare in quel modo disse: "Veramente quest'uomo era Figlio di Dio" ${ }^{67}$. In questi due versetti abbiamo il verbo ópó $\omega$ nel contesto dei titoli messianici

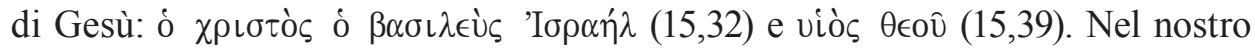

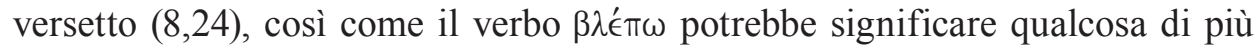
(della mera funzione fisiologica dell'occhio), anche il verbo óó́ $\omega$. Il cieco vede, ma non chiaramente; davanti ai suoi occhi i contorni sono indististinti. Questa immagine della vista non recuperata pienamente può riferirsi anche allo stato del suo spirito. Nel nostro versetto 24 , entrambi i verbi: $\beta \lambda \epsilon ́ \pi \omega$ e ópó́ $\omega$ ricorrono insieme. È interessante che in Mc c'è un altro testo in cui troviamo questi due verbi vicini tra loro: in 4,12 (spiegando perchè Gesù parla in parabole) il Nostro

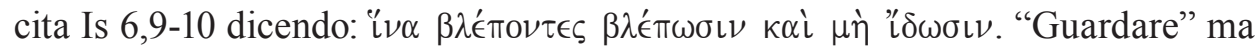
non "vedere" (ascoltare le parabole ma non capire) - è proprio la situazione del nostro cieco!

Gli occhi del cieco non gli consentono di distinguere tra gli uomini e gli alberi. È difficile rispondere alla domanda se Marco, alle parole $\dot{\alpha} \nu \theta \rho \omega ́ \pi$ Tou

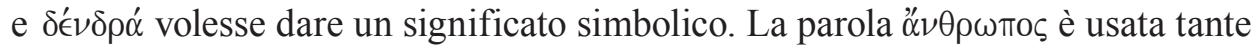
volte (56) nel suo Vangelo, di tanto in tanto per indicare opposizione al disegno

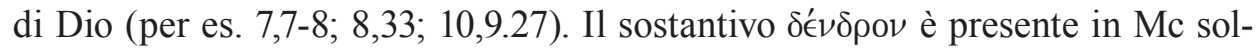
tanto una volta, proprio nel nostro versetto. Gli altri sinottici lo usano di norma nell'immagine di un albero buono che produce frutti buoni e un albero cattivo che produce frutti cattivi ${ }^{68}$. Non si vede allora alcun collegamento chiaro tra gli "uomini" e gli "alberi”. Secondo l'interpretazione simbolica la scelta dell'albero sarebbe legata all'idea di protezione oppure alle tradizioni dei popoli antichi. Gli alberi potrebbero essere stati usati nel nostro racconto come un richiamo al Gdc 9,7-15 (la favola degli alberi che eleggono un re) per polemizzare con la visione errata del re Messia. Alcuni, ancora, vedono nell'immagine degli alberi un'allusione a Is 29,17-18, in cui all'apertura degli occhi è associata la vista di un bosco lussureggiante ${ }^{69}$. Possiamo dunque affermare che Marco usa questo paragone per rendere la confusione che ancora regna nella vista del cieco il quale non riesce ancora a distinguere bene le $\operatorname{cose}^{70}$. Vede soltanto oggetti non meglio identificati che camminavano.

67 Vedi anche l'ultimo brano di Mc in cui ricorre il verbo ópó $\omega$, cioè 16,7. I discepoli sono invitati

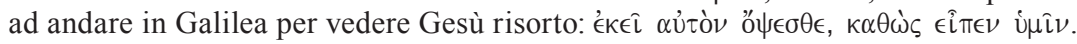

68 Mt 3,10; 7,17-19; 12,33; Lc 3,9; 6,43-44.

69 Per tutte le interpretazioni di tipo simbolico vedi Salvatore, E vedeva, 80-81.

70 "Il confronto, spesso citato, di Epidauro afferma solo che il cieco Alketas di Halieis, guarito da Esculapio, in un primo momento riesce a scorgere le piante nell'ambito del tempio. Il rapporto tra uomini e alberi si trova anche nella psicologia del bambino e di popoli semplici" (Gnilka, Marco, 434). "Gli uomini", visti dal cieco parzialmente guarito potevano essere semplicemente le stesse persone che l'avevano condotto da Gesù (nel v. 22), oppure i discepoli (vedi Malina, Ewangelia, 466). 
Il movimento è reso con il verbo $\pi \epsilon \rho \iota \pi \alpha \tau \epsilon \in \omega$ (usato qui nella forma del participio). Il verbo significa semplicemente "camminare" ma viene anche usato nel significato traslato di "comportarsi" e "vivere" $\pi \in \rho\left\llcorner\pi \alpha \tau^{\prime} \epsilon \omega\right.$ ricorre tre volte nel contesto della guarigione: del paralitico $(2,9)$, della figlia di Giairo $(5,42)$ e del nostro cieco $(8,24)^{72}$. Nei primi due casi $\pi \epsilon \rho \iota \pi \alpha \tau \epsilon \epsilon$ viene usato come l'effetto dell'opera guaritrice di Gesù (il paralitico e la figlia di Giairo dopo il miracolo prendono a camminare). In Mc 8,24 il verbo è presente anche nelle circostanze dell'opera guaritrice di Gesù. Nel nostro versetto non è necessario ricorrere al significato traslato di $\pi \epsilon \rho \iota \pi \alpha \tau \epsilon \in \omega$, basta il significato letterale: il cieco riusciva a vedere degli uomini che camminavano.

Riguardo ai motivi stilistici (come abbiamo già segnalato nella critica testuale)

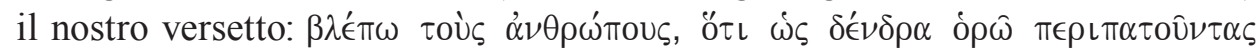
crea tanti problemi, prima di tutto a causa della (non necessaria) introduzione di ö $\tau \iota$ ed anche per un altro verbo che indica vedere, ó $\rho \omega^{73}$. La traduzione italiana della Bibbia di Gerusalemme ${ }^{74}$, Vedo gli uomini, poiché vedo come degli alberi che camminano, non sembra troppo corretta. Cosa significa gli alberi che camminano? Dal punto di vista grammaticale c'è un errore evidente, poichè il sostantivo $\left(\delta \epsilon^{\prime} \nu \delta \rho \alpha\right)$ è neutro, mentre il participio $(\pi \epsilon \rho \iota \pi \alpha \tau o u ̂ \nu \tau \alpha \varsigma)$ è invece al

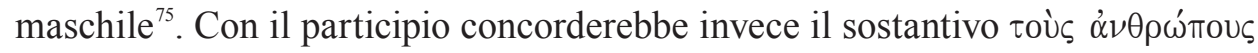
- più favorevole anche a causa del senso del versetto che si potrebbe tradurre come: vedo degli uomini, che camminano, come alberi. Questa è la traduzione che preferiamo ${ }^{76}$. I problemi linguistici nel nostro versetto possono venire dalla traduzione sbagliata dall'aramaico, come spiega per esempio Guelich ${ }^{77}$, ma anche possono venire proprio da Marco che li voleva consapevolmente. In questo modo, anche il linguaggio rende la confusione della vista del cieco, solo parzialmente guarito. Come scrive Ernst: "Le scorrettezze linguistiche della frase rispecchiano,

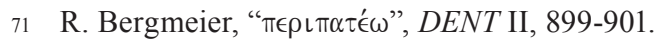

72 Gli altri versetti con questo verbo sono: Mc 6,48-49; 7,5; 11,27; 12,38; 16,12 .

73 Vedi per es. Guelich, Mark 1-8:26, 433; anche France, The Gospel, 325.

74 F. Vattioni (ed.), La Bibbia di Gerusalemme (Bologna: EDB 2004).

75 Nonostante la difficoltà, questa versione è preferita da Salvatore che ci propone anche la sua spiegazione: "Si può obiettare a tale difficoltà (cioè l'incongruenza tra il sostantivo neutro e il participio maschile) sostenendo che ci si trova di fronte ad una costruzione del linguaggio parlato, per cui gli alberi animati potrebbero anche avere una valenza maschile (sarebbe una constructio ad sensum)" (Salvatore, E vedeva, 78).

76 È stata prescelta anche, per es., da France (The Gospel, 325): "not 'I see people who look like walking trees' but 'I see people, and I see them walking like trees'". Lo stesso Gundry (Mark, 417): "Like trees describes the people not $I$ and walking around describes the people not trees or I", anche Guelich (Mark 1-8:26, 433): "I see people walking as trees". Howard rende così la risposta del cieco: "I can make out (blepō) men; they are like trees, except that I can see (horō) them walking" (J. Howard, "Men as Trees, Walking", Scottish Journal of Theology 37 [1984] 165).

77 Guelich, Mark 1-8:26, 433; cfr. Légasse, Marco (Roma: Borla 2000) 412. 
ben rappresentata sotto l'aspetto psicologico, la confusione dell'uomo. Gli alberi, anche nell'idea che se ne fa un cieco, non possono camminare. Evidentemente qui vengono intrecciate l'una nell'altra le prime impressioni" ${ }^{178}$.

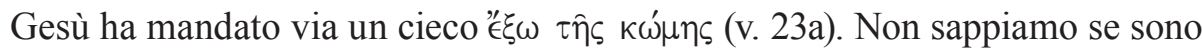
usciti con i discepoli oppure con gli amici che all'inizio lo avevano portato da Gesù. Non possiamo dire a chi si riferisce il sostantivo á $\nu \theta \rho \omega ́$ mous (gli uomini) che sono stati visti dal cieco. Se sono usciti fuori dal villaggio soltanto in due, il sostantivo si potrebbe riferire anche agli abitanti di Betsaida, visti da lontano ${ }^{79}$. La possibilità di percepire il movimento degli uomini, nonostante a lui sembrino alberi, significa "che quest'uomo ha un'idea degli alberi e delle persone, e che quindi non era cieco dalla nascita" ${ }^{80}$. Nel linguaggio biblico non viene specificata la natura della cecità. Soltanto una volta, nei vangeli, si dice che un uomo era cieco dalla nascita (Gv 9,1). Nel nostro racconto, questa informazione manca. Probabilmente il malato ha perso la vista durante il corso della vita. Secondo l'opinione degli specialisti alla persona cieca dalla nascita, quando recupera la vista, va spiegato tutto: i nomi e la natura degli oggetti ${ }^{81}$. Il nostro cieco invece poteva riconoscere (anche se non distintamente) gli uomini, gli alberi ed anche il movimento. Tutto questo significherebbe che non era cieco dalla nascita. Howard spiega la sua malattia come una cataratta grave ${ }^{82}$. Durante il processo di guarigione, il malato prima recupera la vista parzialmente e poi, nella seconda fase, può vedere chiaramente. Interessante è che, alla fine del primo periodo di recupero, della vista, le proporzioni della grandezza degli oggetti risultano confuse: gli oggetti appaiono al malato sovradimensionati. Non è escluso che proprio questo sia avvenuto nel caso del nostro cieco, che vedeva gli uomini come gli alberi ${ }^{83}$. L'insufficienza dei primi gesti terapeutici di Gesù indica il bisogno della seconda fase della guarigione.

78 Ernst, Il vangelo, 362. Alcuni esegeti non si fermano troppo sul significato dei problemi stilistici del versetto. Per es. Johnson ("Mark VIII.22-26", 376) scrive: "although the man's response is awkward in Greek, its meaning is still clear - he can see, but his vision is imperfect".

79 Gundry osserva: "At the distance to which Jesus has withdrawn the patient outside Bethsaida (v.23a), the people who are walking around in the village look so indistinct that the patient compares them to a forest or a clump of trees whose many branches and leaves make them hard to distinguish from one another (esp. when they are waving in the wind, as perhaps implied by the people's milling about)" (Gundry, Mark, 417).

80 Stock, Marco, 149; vedi anche: Gnilka, Marco, 434; Lègasse, Marco, 413.

81 Howard, "Men as Trees", 167.

82 Howard, "Men as Trees", 167.

83 Howard scrive: "Thus in response to the question of Jesus 'Do you see anything' essentially he replied 'Yes, I can make out men: I know they are men because they are walking about, but they are as big as trees!"” (Howard, "Men as Trees", 168). 


\section{d) La seconda imposizione delle mani (v. 25a)}

Gesù, dopo i primi gesti terapeutici, impone di nuovo le mani sugli occhi del cieco parzialmente guarito. Il nesso dimostrativo: $\epsilon \bar{i} \tau \alpha$ può essere reso con: "poi", "quindi", "in seguito", ed indica chiaramente l'inizio della seconda parte del racconto ${ }^{84}$. Anche l'avverbio $\pi \alpha ́ \lambda \iota \nu$ col significato di "di nuovo" indica da una parte l'azione di Gesù, e dall'altra suggerisce la connessione con l'evento precedente ${ }^{85}$. Il gesto di Gesù che segue si riferisce ai due gesti precedenti cioè allo sputo ed all'imposizione delle mani (v. 23). Ancora una volta, Gesù impone

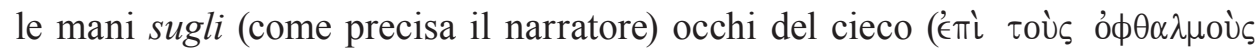

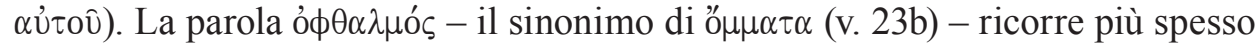
nei vangeli e nel nostro versetto può essere usata per rendere più chiaro il collegamento con il v. $18^{86}$. Ora non si dice niente della saliva, perchè "si tratta soltanto di completare la guarigione" ${ }^{87}$. Gli occhi del cieco potevano essere ancora umidi dopo la prima applicazione ${ }^{88}$. La seconda imposizione delle mani viene spiegata dagli esegeti in diversi modi: a) la spiegazione narrativa parla della grandezza e della difficoltà della guarigione ${ }^{89}$, oppure solo del gusto del narratore senza alcuna finalità performativa ${ }^{90}$; b) la spiegazione di tipo psicologico propone che la guarigione "sarebbe ritardata al fine di ottenere una maggiore attenzione da parte del guarito" "91; c) la spiegazione simbolica nell'apertura degli occhi del cieco vede l'avanzamento degli apostoli nella comprensione del mistero di Gesù (come vedremo nella parte finale del lavoro ${ }^{92}$; d) la spiegazione medica suggerisce che, nel caso del nostro cieco, si può riconoscere il processo di guarigione da una malattia chiamata "prosopagnosia"

84 Nel Nuovo Testamento è usato 15 volte, delle quali 4 volte in $\mathrm{Mc}$ (più spesso che in tutti gli evanł gelisti), sempre nel cap. 4 (Mc 4,17 e due volte in Mc 4,28) e una volta proprio nel nostro versetto. In tutte e tre le ricorrenze (in Mc 4) la congiunzione viene usata con valore temporale. Un uso simile si ritrova anche negli altri Vangeli: Lc 8,12; Gv 13,5; 19,27; 20,27. In Mt non ricorre mai.

$85 \Pi \alpha \dot{\lambda} \iota \nu$ in Mc ricorre 28 volte, spesso collegato con verbi che esprimono il movimento di Gesù e dei suoi discepoli (Mc 2,1.13; 3,1.20; 5,21; 7,31; 8,13; 11,27; 14,39s) oppure con l'insegnamento di Gesù (Mc 4,1; 10,1.24.32); è usato spesso anche nel racconto della passione (Mc 14,61.69s; 15,4.12s).

86 Gundry, Mark, 418.

87 Lègasse, Marco, 413.

88 Così lo spiega Gundry: "This time there is no need for further saliva; the man's eyes are still moist from the first application" (Gundry, Mark, 418).

89 Gundry, Mark, 418.

90 Gnilka, Marco, 434.

91 Salvatore, E vedeva, 96.

92 Salvatore dice ancora dell'ipotesi razionalistica, rappresentata da Bultmann, secondo la quale la difficoltà della guarigione "sarebbe stata redazionalmente elaborata in modo tale da essere resa più accettabile dal punto di vista razionale" e dalla spiegazione di tipo non-simbolico (Salvatore, E vedeva, 96).

93 Questo tipo di malattia si riferisce alla distinzione tra la visione ottica e la percezione (ingl. "optical sight" e "cognitive perception"). Dopo la prima fase della guarigione, un cieco avrebbe 
La seconda fase della guarigione non vuole indicare un momentaneo insuccesso del taumaturgo. Da una prospettiva umana, Gesù ha già fatto miracoli ben più grandi, come la guarigione dell'indemoniato geraseno (Mc 5,1-20) oppure la risurrezione della figlia di Giairo (Mc 5,35-43). I due momenti del nostro racconto ci vogliono indicare che è proprio la guarigione del cieco il miracolo più difficile e più grande di tutti quelli operati da Gesù. Il suo significato simbolico, come vedremo più avanti, può riferirsi all'evolversi della comprensione chiara del processo della rivelazione - il processo più difficile di tutti.

\section{e) La vista ristabilita (v. 25b)}

Dopo le due fasi della guarigione, il cieco recupera la vista. L'effetto dell'azione

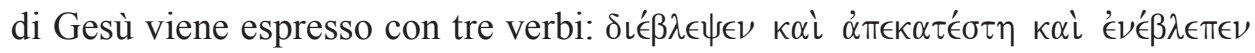
$\tau \eta \lambda \alpha \nu \gamma \omega \hat{\omega} \varsigma \ddot{\alpha} \pi \alpha \nu \tau \alpha$. Il primo dei tre: $\delta\llcorner\alpha \dot{\beta} \lambda \epsilon \pi \omega$ non ricorre mai nei LXX; e nel Nuovo Testamento lo ritroviamo soltanto tre volte. In Mt 7,5 si parla della trave dell'occhio che deve essere tolta per poter vedere bene. Nello stesso contesto, il verbo viene usato in Lc 6,42. In entrambi i casi $\delta\llcorner\alpha \dot{\beta} \lambda \epsilon \pi \omega$ significa "vedere chiaramente" 94 . Questo significato può essere usato anche nel nostro versetto, dove $\delta$ l'́ $\beta \lambda \in \psi \epsilon \mathcal{V}$ viene impiegato in contrasto con $\beta \lambda \lambda^{\prime} \pi \omega$ del versetto precedente. Prima l'uomo riusciva a vedere in modo indistinto, ora, dopo la seconda imposizione delle mani di Gesù,è in grado di vedere completamente, distinguendo gli oggetti in modo chiaro. L'uso del verbo all'aoristo indica un punto nel tempo, un momento preciso, in cui la vista è stata recuperata ${ }^{95}$, vale a dire proprio dopo il secondo intervento di Gesù.

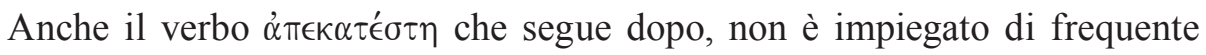
nel Nuovo Testamento, lo troviamo infatti solo 8 volte (6 volte nei sinottici). Prendendo questo verbo nei contesti in cui viene usato, si può cogliere il suo

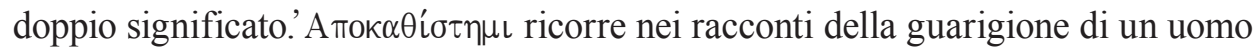

ricuperato la possibilità di vedere in senso fisiologico (come se fosse stato guarito dalla cataratta) e in seguito, nella seconda fase della guarigione, il cieco avrebbe ricuperato la capacità di una piena cognizione. Nel caso della prosopagnosia, gli occhi del malato funzionano in modo normale, ma sopravvengono disturbi a livello della percezione (vedi: B. Glenney - J.T. Noble, "Perception and Prosopagnosia in Mk 8.22-26", JSNT 37 (2014) 71-85; vedi anche Boyd, "Is a Basis", 85). Da Howard la malattia del cieco viene chiamata come "aphakia" che significa "the loss of the crystalline lens of the eye [...]. If this were the case, then it would need to be assumed that the blind man suffered from severe cataracts" (Howard, "Men as Trees", 168).

94 Nella letteratura greca non biblica il verbo è presente con due significati: a) guardare intensaa mente, fissare attentamente ("look intently") e b) distinguere, vedere chiaramente ("distinguish, see clearly") (Johnson, The Blind Man, 377). J. Marcus ("A Note on Markan Optics", NTS 45 [1999] 255) definisce il significato del verbo in senso letterale come "saw through", aggiungendo anche questa spiegazione: "this suggests that the man's sight-beams have broken through the barriers (cataracts?) in his eyes".

95 Johnson, The Blind Man, 378. 
dalla mano inaridita (Mt 12,13; Mc 3,5; Lc 6,10). Il primo significato, allora, è associato al ristabilimento della salute. L'altro invece si può vedere in Mt 17,11 e Mc 9,12, in cui il testo parla di Elia che deve venire per ristabilire ogni cosa ( $\dot{\alpha} \pi 0 \kappa \alpha \tau \alpha \sigma \tau \eta \dot{\sigma} \sigma \in \mathrm{L} \pi \dot{\alpha} \nu \tau \alpha$ in Mt 17,11 e $\dot{\alpha} \pi 0 \kappa \alpha \theta \iota \sigma \tau \dot{\alpha} \nu \in \mathrm{L} \pi \dot{\alpha} \nu \tau \alpha$ in Mc 9,12). Questo secondo significato concorda con i LXX, in cui nei testi profetici (Ger 16,15; $23,8 ; 24,6$; Os 2,$3 ; 6,11 ; 11,11)$ si tratta della reintegrazione alla fine dei tempi, di Israele dalla dispersione esilica. Il significato del nostro verbo: "ristabilire, riportare nella condizione originaria" ${ }^{96}$ si può riferire allora ad una persona concreta oppure a tutto il popolo (ristabilimento escatologico). In ambedue i casi $\dot{\alpha} \pi о \kappa \alpha \theta \dot{\imath} \sigma \tau \eta \mu \iota$ significa tornare alla condizione originaria. Nel nostro racconto il cieco recupera allora la condizione di santità; viene reintegrato nelle facoltà perdute; ritorna allo stato originario, ritorna com'era prima ${ }^{97}$. Questo rimando al passato potrebbe confermare che il nostro malato non fosse cieco dalla sua nascita, bensì fosse stato colpito, nel corso della sua vita, da un disturbo alla vista. Tuttavia l'enfasi viene posta sul tempo presente: ha recuperato la vista ed adesso può vedere bene ${ }^{98}$, la funzione propria degli occhi è stata ripristinata ${ }^{99}$.

Il terzo verbo, $\iota^{\prime} \nu \in \hat{\epsilon} \beta \lambda \in \pi \in \nu$, introdotto (come entrambi i verbi precedenti) dal

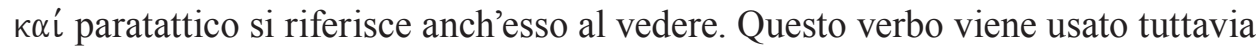
con sfumature più intense del semplice "vedere". Lo usano tutti gli evangelisti, ma nel linguaggio marciano ricorre più spesso (quattro volte) ${ }^{100}$. Il Nostro lo usa per la prima volta proprio nel nostro racconto $(8,25)$; poi nel racconto dell'uomo

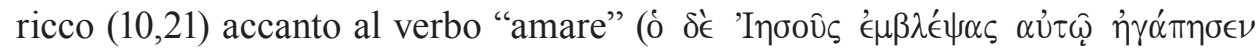

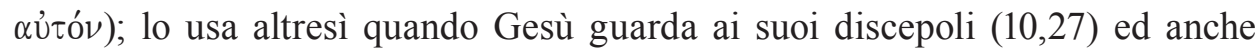
quando la serva del sommo sacerdote vede Pietro che stava a scaldarsi $(14,67)$. Marco usa quindi questo verbo con un significato intenso, nel senso di "capire una persona o una situazione" ${ }^{101}$; una sfumatura di intensità ancora maggiore viene data dalla preposizione $€ \nu$, grazie alla quale possiamo renderlo con "guardare dentro", "guardare intensamente" ${ }^{102}$. Questo ci mostra chiaramente che la

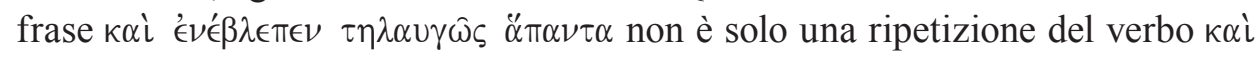
$\delta \iota^{\prime} \in \beta \lambda \in \psi \in \nu$ analizzato in precedenza.

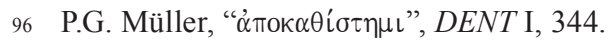

97 Salvatore, E vedeva, 99.

98 Gundry, Mark, 418.

99 Forse come opposizione a Mc 3,5 (vedi: France, The Gospel, 325).

100 In Mt, Lc e Gv soltanto due volte.

101 Con un senso più intenso '́ $\mu \beta \lambda \epsilon^{\prime} \pi \omega$ viene usato anche in Gv. In Gv 1,36 Giovanni il Battista

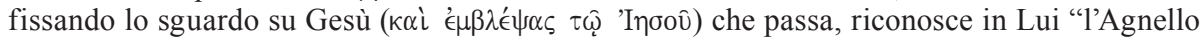

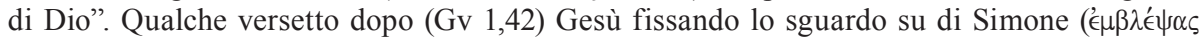

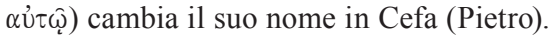

102 Cfr. Johnson, The Blind Man, 378.
} 
È anche importante tenere nel debito conto lo scambio dei tempi. I primi

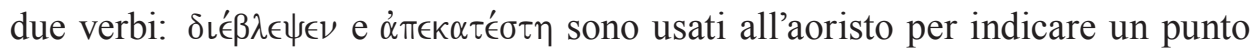
preciso del tempo, vale a dire il momento in cui il cieco ha recuperato del tutto la vista. Il verbo '€ $\nu^{\prime} \beta \lambda \in \pi \in \nu$ è invece all'imperfetto, trattandosi di un'azione che viene considerata come non terminata: il cieco ha cominciato a vedere; la sua guarigione era stabile, definitiva. Per lui inizia così una situazione nuova, una fase nuova della sua vita ${ }^{103}$. Come oggetto del verbo ' $\epsilon \mu \beta \lambda \lambda^{\prime} \pi \omega$ è usato un accusativo neutro plurale: $\ddot{\alpha} \pi \alpha \nu \tau \alpha$, ossia "tutte le cose". Il neutro plurale sta a significare la completezza dell'oggetto visibile, completezza che viene vieppù rafforzata dall'avverbio: $\tau \eta \lambda \alpha u \gamma \omega \hat{\varsigma}$ che nel Nuovo Testamento si trova usato soltanto una volta - proprio nel nostro versetto. Questo termine è conosciuto nella letteratura greca come termine poetico dal significato: "a distanza" 104, "splendente in lontananza, chiaro come il sole" ${ }^{105}$.

Alla fine della parte centrale del racconto, Marco descrive con precisione

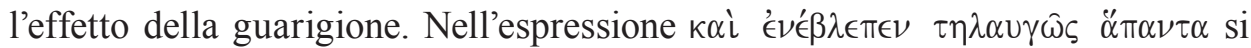
colgono due dimensioni della percezione visiva: "vedere tutte le cose" e "vedere a distanza". Come scrive Salvatore: "La presenza di entrambe indica la globalità. Il cieco vede tutto quello che si può vedere" ${ }^{106}$. La presenza dei verbi: $\alpha \nu \alpha \beta \lambda \epsilon ́ \pi \omega$,

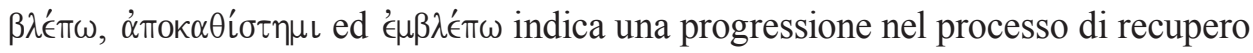
della vista: il cieco comincia con l'alzare gli occhi, poi vede pian piano, in modo graduale, in maniera ancora indistinta e infine riesce a vedere (probabilmente così come avveniva prima della sua malattia) chiaramente tutte le cose. Il nostro racconto è costruito come un cammino, come un percorso:l'uomo condotto personalmente da Gesù, passa gradualmente dalla cecità alla vista perfetta.

\subsection{La conclusione (v. 26)}

Nella parte conclusiva della spiegazione del testo analizziamo l'ultima tappa dell'incontro di Gesù con l'uomo ormai guarito. Dopo la descrizione della terapia, l'uomo con la vista recuperata viene mandato a casa (v. 26a). Gesù gli proibisce tuttavia di entrare nel villaggio (v. 26b).

103 France, The Gospel, 325; lo stesso anche Gundry (Mark, 418): "The switch from aorist to

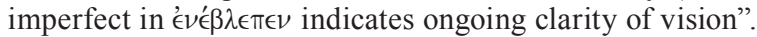

104 Salvatore, E vedeva, 101.

105 Gnilka, Marco, 434.

106 Salvatore, E vedeva, 101. 


\section{a) Il rimando a casa (v. 26a)}

Dopo l'incontro con Gesù, il cieco miracolato viene (ri)mandato a casa. Dapprima (v. 23), Gesù deve prenderlo per mano per farlo uscire dal villaggio; adesso è in grado di andare da solo, non ha bisogno di essere accompagnato da nessuno. Nell'ultima fase dell'incontro con Gesù, egli viene "mandato". Nel Vangelo di Marco, il verbo $\alpha \operatorname{\pi } \sigma \sigma \tau \in \epsilon \lambda \lambda \omega$ significa in genere "inviare", "mandare" ma, a seconda del contesto, può assumere sfumature diverse ${ }^{107}$. Soltanto una volta - proprio nel nostro versetto $(8,26 a)-\dot{\alpha} \pi 0 \sigma \tau \tau^{\prime} \lambda \lambda \omega$, viene usato da Gesù e non si riferisce ai discepoli bensì ad un uomo guarito. Su questo verbo torneremo ancora nella parte successiva, analizzando il v. $26 \mathrm{~b}$.

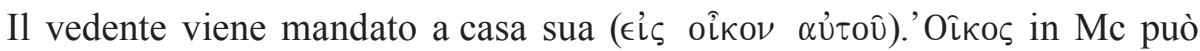
riferirsi ad un luogo isolato, lontano dalla folla (cfr. 7,17.30; 9,28), ma anche all'opposto, vale a dire a un luogo affollato, pieno di gente. Quando Gesù entra in una casa, si radunano tante persone $(2,1 ; 3,20$; anche in 5,38 , quando si parla della casa del capo della sinagoga, lo si riferisce alla gente). Quando Gesù manda a casa un paralitico guarito $(2,11)$, il narratore dice che lui se ne andò in presenza di tutti. Si vede allora che la casa non è staccata dalla presenza della gente ed "andare a casa" non significa "andare in un luogo isolato", dove non ci sono altre persone. Per spiegare il nostro versetto può essere utile il confronto con Mc 5,19, in cuil'indemoniato geraseno, guarito da Gesù, viene mandato a casa

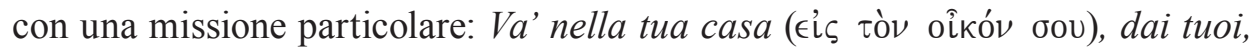

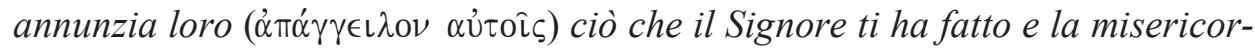
dia che ti ha usato. Proprio in questo contesto potremmo comprendere anche il nostro versetto. Il cieco miracolato viene mandato a casa non per tacere, né per star da solo, bensì per annunziare agli altri ciò che il Signore gli ha fatto: una volta che è stato toccato da Gesù, egli può vedere chiaramente e viene mandato, come i discepoli (cfr. Mc 3,14; 6,7), per predicare.

\section{b) Proibizione dell'entrata nel villaggio (v. 26b)}

Il rimando a casa è legato a una condizione: il vedente non può andare nel villaggio. Come già visto nella critica testuale, questa parte del v. 26 non è sempre identica nei vari manoscritti. Questo significa che, sin dall'inizio, c'erano problemi

107 Il semplice "mandare" lo troviamo in 3,31; 6,17.27; 11,3; 12,2-5.13. Questo verbo si riferisce qualche volta a Gesù che viene mandato dal Padre $(9,37 ; 11,6)$. Cinque volte in Mc (e questo

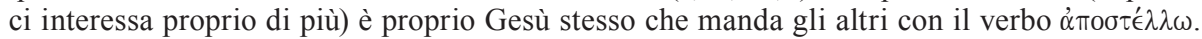
In 3,14, Egli manda i suoi discepoli a predicare e a scacciare i demoni; in 6,7 li manda a due a due; in 11,1 essi devono andare nel villaggio e alla fine $(14,13)$ sono mandati per preparare la Pasqua. 
con la sua interpretazione e ogni tanto si aggiungevano diverse spiegazioni (non soltanto non andare nel villaggio ma anche non dire a nessuno con qualche variazione linguistica). Come il testo più vicino all'originale, abbiamo scelto la

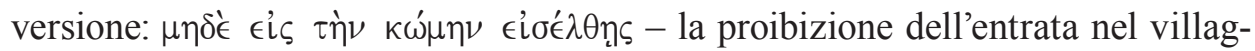

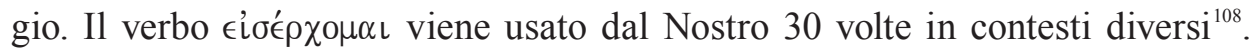
Nel nostro versetto possiamo semplicemente prendere il primo significato che esprime l'entrare in un luogo (nel nostro caso: il villaggio). La proibizione di entrare nel villaggio viene espressa dalla particella $\mu \eta \delta \delta^{\prime}$ che è usata di solito in funzione copulativa con il significato di: "né", "e non", "neppure"109. Di norma, la negazione $\mu \eta \delta \epsilon$ è preceduta da un'altra negazione ${ }^{110}$. Nel nostro versetto, anche perché manca la prima negazione, si vede che c'è chiaramente qualcosa che non $\mathrm{va}^{111}$. Ciònonostante, il significato è collegato con la proibizione di entrare nel villaggio. La logica della conclusione del racconto può essere salvaguardata soltanto se il cieco non ha la sua casa nel villaggio dal quale Gesù lo conduce

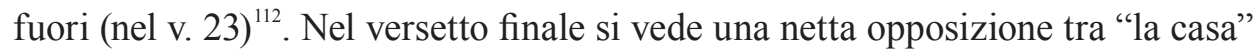

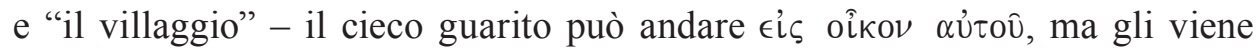

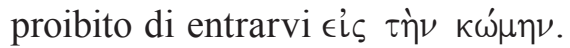

Le spiegazioni del v. 26 nei commentari degli esegeti sono diverse ma possiamo dividerle in due gruppi: per i primi, Gesù manda l'uomo guarito a casa perché vuol mantenere "il segreto messianico" 113 ; per i secondi, invece, il rimandare a casa non ha niente a che fare con "il segreto messianico" di Gesù. Il primo gruppo di studiosi si basa sul fatto che il v. 26 pone in contrapposizione la "casa" e il "villaggio", cioè un "luogo segreto" e un "luogo pubblico". Come osserva Gnilka: "La diffusione della rivelazione non deve avvenire adesso, ma soltanto in un momento successivo, quando il taumaturgo Gesù può essere visto come il Crocifisso" 114 . Alla fine dell'incontro con il cieco guarito, è ancora troppo presto e Gesù non vuole che lui divulghi il miracolo ${ }^{115}$. Gesù lo manda a casa per non destare false aspettative messianiche ${ }^{116}$. È interessante che l'ordine di tacere, di

108 Con indicazioni di luogo significa semplicemente "entrare” (per es. Mc 1,22), in rapporto con le persone viene usato particolarmente per dire che gli spiriti maligni ne prendono possesso, cioè entrano nelle persone (per es. Mc 9,25). Il terzo significato ricorre nei discorsi sull'entrata nel regno di Dio (Mc 10,15).

109 Cfr. BDR, $\S 445$.

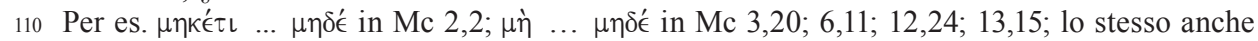
negli altri vangeli, per es. Mt 6,25; 10,9s; Lc 12,22; 14,12 etc.

111 Cfr. BDB, $\$ 445$.

112 "Do not enter the village [...] only makes sense if the man did not actually live in the village" (Guelich, Mark 1-8:26, 434).

113 “It supposedly supports Mark's segrecy motif”' (Guelich, Mark 1-8:26, 343).

114 Gnilka, Marco, 435.

115 Cfr. Edwards, The Gospel, 244.

116 Moloney, The Gospel, 164. 
non destare "il segreto messianico" di Gesù si riferisce qualche volta anche ai discepoli (Mc 5,43; 8,30; 9,9) e loro osservano quest'ordine. Così si comporta probabilmente anche il nostro ex-cieco. Come i discepoli, anche il cieco guarito osserva "il segreto messianico" di Gesù.

Al contrario, gli altri studiosi sostengono che il divieto di entrare nel villaggio non ha niente a che fare con "il segreto messianico". È vero che Gesù vuol evitare all'ex-cieco ogni contatto con le persone dalle quali l'ha allontanato ${ }^{117}$. La proibizione è simile all'ordine di tacere intimato chiaramente in altri passi (per es. 1,44; 7,36). Pur tuttavia, ciò che sorprende è proprio che, al contrario di quanto avviene in brani analoghi, nel nostro racconto l'ordine non viene trasgredito (cfr. 1,45; 7,36). Come suggerisce Lègasse: "Forse Marco avrebbe potuto prolungare l'episodio raccontando che il miracolato, nella sua patria, si comporta come l'ex-indemoniato in 5,20: in questo modo avrebbe ristabilito lo schema divieto - trasgressione" ${ }^{\prime 118}$. Non c'è questo schema nel nostro racconto. La sua mancanza può essere causata da motivi redazionali dello schema del cammino di Gesù: quando il divieto di parlare veniva trasgredito, Gesù si doveva spesso fermare a causa delle folle che venivano a Lui (per es. 1,45). Dopo l'incontro con il nostro cieco, che non ha trasgredito l'ordine di tacere, Gesù poteva partire liberamente per Cesarea di Filippo $(8,27)^{119}$. Si può vedere anche il legame formale tra la conclusione della nostra pericope e l'inizio del brano

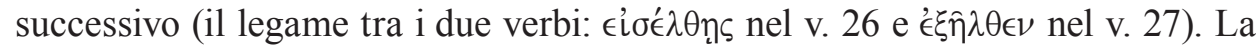
mancanza dello schema: "divieto - trasgressione" può essere dovuta anche al fatto che l'ordine di non entrare nel villaggio non ha niente a che fare con "il segreto messianico" di Gesù.

Molto interessante è anche la spiegazione di Gundry ${ }^{120}$. Anche lui comincia spiegando il rapporto casa-villaggio come un'opposizione tra luogo privato e pubblico. Il villaggio dal quale il cieco è stato condotto da Gesù può significare (come luogo pubblico) una piazza nel centro del villaggio, dove probabilmente il cieco - come anche gli altri malati -, stava mendicando. Il fatto che Gesù gli dice di non andare nel villaggio vuol dire: non andare più nella piazza come mendicante. Lo manda a casa, che non deve essere necessariamente fuori del villaggio. È vero che Gesù, dopo un miracolo, ordina spesso il silenzio $(1,44 ; 5,43)$, una volta persino alla folla $(7,36)$, ma per un ordine del genere noi ci aspetteremmo delle

117 Cfr. per es. S. Haręzga, Jezus i Jego uczniowie. Model chrześcijańskiej formacji w Ewangelii wedlug św. Marka (Lublin: Wydawnictwo KUL 2007) 196.

118 Lègasse, Marco, 415.

119 France (The Gospel, 325) pone come una domanda: "Are we to understand that Jesus is simply 'buying time' to allow himself and his disciples to leave the area before the news gets around [...]?"

120 Gundry, Mark, 418-419. 
parole specifiche che nel nostro racconto invece mancano ${ }^{121}$. Andare a casa, non nel villaggio, significherebbe allora non star più sulla piazza del villaggio o della città per chiedere soldi come mendicante. Come già abbiamo visto, "andare $\epsilon i \zeta$ оî́ор" non deve significare "stare zitto". In Mc 2, 11-12, andare a casa non ha niente a che fare con il tener nascosto il miracolo (lo stesso avviene anche in 5,19; 7,29-30). Anzi, un altro cieco, Bartimèo, dopo la guarigione della vista non soltanto non deve andare a casa, ma può seguire Gesù per la strada $(10,52)$. La mancanza della formula del segreto ed anche i testi paralleli ci indicano che Mc 8,26 non dice niente né del tener nascosto il miracolo, né del segreto messianico. Il significato del versetto potrebbe essere totalmente opposto: il vedente deve mostrare la sua guarigione; adesso non deve camminare con gli uomini che lo portano per mano, ma può andare da solo ${ }^{122}$. Per sostenere l'ipotesi di Gundry ci

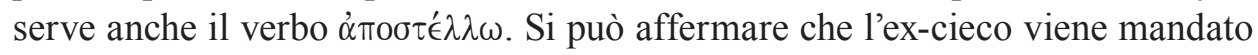
da Gesù così come sono stati mandati i discepoli: con una missione. Prima $(3,14)$ essi vengono mandati a predicare e a scacciare i demoni, poi Gesù li manda a due a due (6,7). In 11,1 e 14,13 si dice soltanto dei due discepoli; l'importante

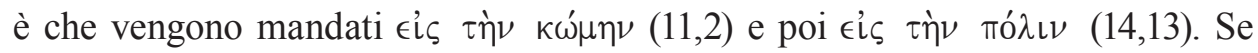

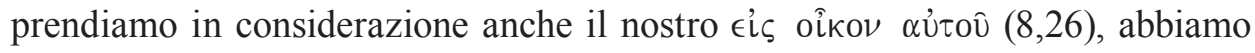

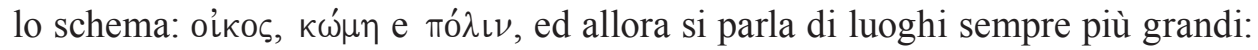
casa, villaggio e città. I discepoli in 11,2 sono stati mandati per portare a Gesù un asinello, subito prima dell'ingresso in Gerusalemme; poi $(14,13)$ vanno per

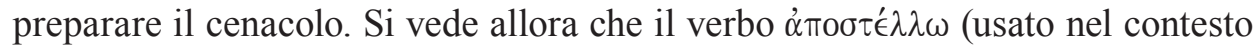
di Gesù e dei suoi discepoli) è strettamente collegato con il mistero pasquale.

Tutte le spiegazioni del v. 26 hanno soltanto un valore di ipotesi. Come abbiamo visto, ci sono argomenti a favore del segreto messianico (Gesù non vuole ancora che la sua identità sia conosciuta; è troppo presto), ma d'altra parte abbiamo visto che mandare a casa non deve equivalere a tacere. Forse non nella città né nel villaggio, ma proprio a casa sua il miracolato deve dare testimonianza del suo incontro personale ed intimo con Gesù. Il nostro ex-cieco non viene mandato a Betsaida, famosa per la sua incredulità. Viene mandato a casa sua, dai suoi che non possono non sapere della sua malattia. Adesso, vedendo il miracolo della guarigione, potranno riconoscere in Gesù non soltanto un taumaturgo ma anche il Messia.

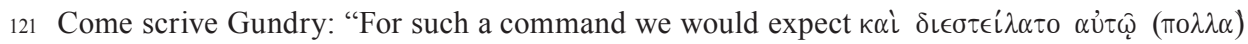

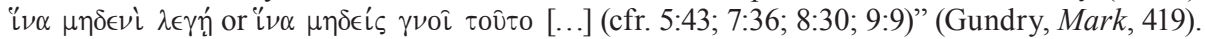

122 Gundry osserva: "This verse carries a demonstration of healing: the man can now see to go home without needing people to take him there as he did need them to bring him to Jesus (v. 22)" (Gundry, Mark, 419). 


\section{La posizione della pericope nel suo contesto}

Dopo la spiegazione del testo.'] non possiamo non rivolgerci al contesto per comprendere la posizione e il significato del nostro racconto nel Vangelo di Marco. Dapprima analizzeremo la posizione della guarigione del cieco nel contesto immediato (ossia riguardo a ciò che precede e ciò che segue direttamente il nostro racconto), poi inquadreremo il nostro brano in un contesto più ampio, vale a dire in tutto il Vangelo.

\subsection{La pericope nel contesto immediato}

Prendiamo in considerazione il brano che precede la guarigione del cieco (cioè $8,14-21)$ nonché il racconto che lo segue $(8,27-30)$. Per cogliere meglio gli elementi comuni e gli elementi diversi tra i brani presi in esame, seguiremo lo schema: l'attività di Gesù, i destinatari e le reazioni dei destinatari.

Nella pericope che precede la guarigione del cieco, Gesù si trova sulla barca con i suoi discepoli. La sua attività è anzitutto un insegnamento. Abbiamo

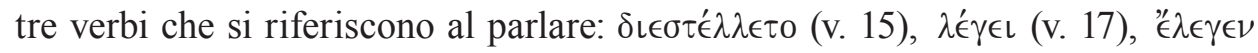
(v. 21). I verbi sono usati all'imperfetto (il primo e il terzo verbo) oppure al presente storico ed esprimono un'azione durativa. Gesù ammoniva i suoi discepoli e parlava loro. Comincia il suo insegnamento con due imperativi: ópât $\epsilon, \beta \lambda \epsilon \epsilon \epsilon \epsilon \epsilon$ (v. 15), ammonendo che i discepoli devono fare attenzione al lievito dei farisei (probabilmente si riferisce all'incontro con i farisei nel brano precedente, 8,11-13, ma anche agli altri brani). Nella seconda parte del suo insegnamento (vv. 19-20) Gesù ricorda ai suoi discepoli le moltiplicazioni dei pani (6,30-44; 8,1-9). Due volte pone domande che si riferiscono al numero dei pani, delle persone e delle ceste colme di cibo. Tra il suo ammonimento (v. 15) e le domande (vv. 19-20), all'inizio del v. 17 troviamo il participio yvoús - Gesù, conoscendo la loro incapacità di capire cosa significhi il lievito dei farisei e conoscendo la loro paura dovuta alla mancanza del pane, ricorda loro quel che è successo poco prima e che hanno visto con i loro occhi. L'attività di Gesù in questo brano finisce

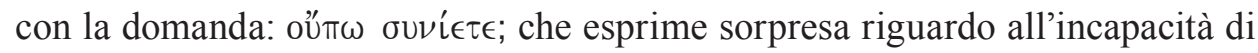
capire dei discepoli.

I destinatari del brano sono soltanto i discepoli di Gesù. Sulla barca non ci sono altre persone. Sono loro quelli che si dimenticano ( $\epsilon \pi \in \lambda \dot{\alpha} \theta 0 \nu \tau 0)$ e poi si preoccupano della mancanza del pane (v. 14). Quando Gesù parla del lievito dei farisei e di Erode (v. 15), non lo ascoltano, ma la loro attenzione si concentra

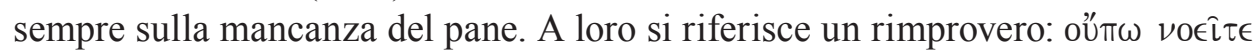

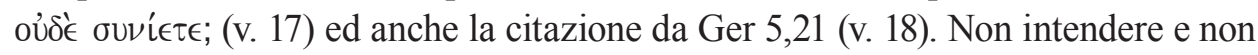


capire, avere gli occhi ma non vedere e gli orecchi ma non udire - questa è una caratteristica dei discepoli. Essi ricordano i fatti anche nei dettagli (rispondono bene alle domande di Gesù nei vv. 19-20), ma non capiscono il senso di tutto ciò che avviene attorno a loro.

Non conosciamo la reazione dei destinatari in questa pericope. L'ultima do-

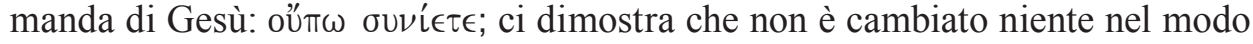
di pensare e di capire dei discepoli. Nonostante le parole di Gesù e il ricordo delle sue opere non capiscono ancora (v. 21). La loro cecità spirituale non viene ancora superata.

Il "filo rosso" che collega 8,14-21 e 8,21-26 è proprio l'affermazione: "avere gli occhi ma non vedere”. L'immagine della cecità spirituale dei discepoli viene sviluppata proprio nella guarigione della cecità fisica. Questo miracolo esige da Gesù un impegno molto intenso. $\mathrm{Ci}$ vogliono due fasi prima del risultato pieno. Il cieco non può recuperare la vista da solo. Dev'esserci l'intervento di Gesù stesso che lo tocca con le mani e con la saliva. Anche i discepoli non possono giungere da soli alla vista perfetta: essi sono ancorati all'impegno di Gesù.

Nella pericope seguente $(8,27-30)$ Gesù parte con i suoi discepoli verso i villaggi vicini a Cesarèa di Filippo. L'attività di Gesù si svolge con il verbo

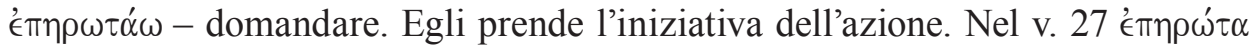
- rivolge una domanda ai suoi discepoli, vuol sapere cosa la gente dice di lui. Dopo la risposta, (v. 29) Gesù rivolge ai discepoli ancora una volta la stessa domanda, per conoscere la loro opinione su di lui. Dopo le parole di Pietro,

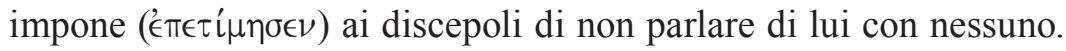

I destinatari dell'azione di Gesù (come anche in 8,14-21) sono soltanto i suoi discepoli. Essi partono insieme a Gesù (v. 27) e rispondono alle sue domande. Alla prima domanda possono rispondere tutti; sanno bene cosa dice la gente. Quando la domanda viene rivolta a loro, risponde invece soltanto uno - Pietro:

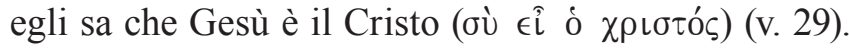

Il brano non dice niente della reazione dei discepoli. I versetti che seguono (8,31-33) mostrano che, nonostante la sua professione di fede, Pietro prende Gesù in disparte e prende a rimproverarlo (v. 32) in quanto, non vuol saperne della passione e morte del Figlio dell'uomo.

Confrontando la guarigione del cieco e la professione di fede di Pietro, si può osservare qualche somiglianza. Entrambe le scene si svolgono in un luogo riservato, senza la presenza delle folle. In ambedue i racconti Gesù interviene in due momenti: per due volte impone le mani sul cieco $(8,23.25)$ e per due volte rivolge la stessa domanda ai suoi discepoli $(8,27.29)$. Come dopo la prima imposizione delle mani il cieco non vede ancora bene, così dopo la prima domanda i discepoli riferiscono soltanto quello che gli altri dicono di Gesù. E, come dopo il secondo intervento del taumaturgo il cieco recupera la vista 
perfetta così, dopo la seconda domanda, Pietro confessa l'identità di Gesù come il Cristo. Tutti e due i racconti finiscono con un'ammonizione di Gesù: il cieco non può entrare nel villaggio $(8,26)$; i discepoli invece non possono divulgare l'identità del Cristo.

Questo paragone mostra che fra la guarigione del cieco e la professione di fede di Pietro ci sono diverse somiglianze. D'altra parte vanno notate anche le differenze, tra le quali la più grande sembra essere la differenza nell'attività di Gesù. Nel racconto della guarigione, Gesù esprime la sua attività attraverso le parole ma anche con i gesti. In 8,27-30, ci sono soltanto le parole. Lo stesso avviene anche nel brano che precede la guarigione (8,14-21): Gesù sulla barca non compie gesti, bensì si limita a parlare. L'altra differenza è riscontrabile anche per i destinatari: In 8,27-30 e 8,14-21 ci sono i discepoli che parlano con Gesù, invece in 8,22-26 non si dice niente dei discepoli; il loro posto è occupato dal cieco. Anche la reazione dei destinatari è diversa: i discepoli, nonostante il contatto e il dialogo con Gesù, sembrano avere gli occhi chiusi (in 8,27-30 soltanto Pietro riconosce l'identità di Gesù, neanche non troppo bene, come ci mostra il brano che segue: 8,31-33). Il cieco invece può vedere chiaramente ed a distanza. La sua guarigione è duratura; è in grado di camminare da solo. Le nostre osservazioni saranno più chiare nello schema seguente:

\begin{tabular}{|l|l|l|l|}
\hline $\begin{array}{l}\text { 1. L'azione di } \\
\text { Gesù: }\end{array}$ & $\begin{array}{l}\text { Mc 8,14-21 } \\
\text { Gesù parla, fa } \\
\text { domande ai } \\
\text { discepoli, }\end{array}$ & $\begin{array}{l}\text { Mc 8,22-26 } \\
\text { parole, ma anche } \\
\text { molte azioni } \\
\text { (prende il cieco per } \\
\text { mano, lo conduce } \\
\text { fuori, sputa, due } \\
\text { volte impone le } \\
\text { mani), }\end{array}$ & $\begin{array}{l}\text { Mc } \\
\text { parla, due volte } \\
\text { fa domande ai } \\
\text { discepoli, }\end{array}$ \\
\hline $\begin{array}{l}\text { 2. I destinatari: } \\
\text { destinatari: }\end{array}$ & i discepoli di Gesù, & $\begin{array}{l}\text { il cieco (all'inizio } \\
\text { anche le persone } \\
\text { anonime che lo } \\
\text { portano a Gesù), }\end{array}$ & i discepoli di Gesù, \\
\hline non capiscono, & $\begin{array}{l}\text { il cieco vede } \\
\text { chiaramente e } \\
\text { a distanza, può } \\
\text { camminare da solo, }\end{array}$ & $\begin{array}{l}\text { è Gesù (Mc 8,31-33 } \\
\text { mostra che anche } \\
\text { lui non capisce } \\
\text { ancora). }\end{array}$ \\
\hline
\end{tabular}

Questo schema ci mostra che fra 8,14-21 e 8,27-30 ci sono forti somiglianze: Gesù parla con i suoi discepoli che non capiscono bene la sua identità. In mezzo 
sta la pericope della guarigione del cieco $(8,22-26)$. La nostra scena illumina ciò che la precede e ciò che la segue: Gesù, così come ha aperto gli occhi del cieco, può aprire anche gli occhi dei suoi discepoli ${ }^{123}$. Quel che è successo al cieco è come un programma per il rapporto di Gesù con i suoi discepoli ${ }^{124}$. Alla fine, anche loro vedranno tutto chiaro.

\subsection{Contributo della pericope al messaggio dell'intero Vangelo di Marco}

Dopo l'analisi della pericope nel contesto immediato, vogliamo anche vedere il suo significato e la sua importanza in tutto il Vangelo del Nostro. Per approfondirei legami della nostra pericope all'interno di tutto il Vangelo, è necessario averne presente la struttura, che schematizziamo come segue ${ }^{125}$ :

Inizio: Preparazione del ministero di Gesù e sua venuta in Galilea (1,1-13), Prima parte: La missione di Gesù in Galilea $(1,14-8,26)$, Seconda parte: Passione, morte e risurrezione di Gesù $(8,27-16,8)$, Appendice: Apparizioni di Gesù risuscitato (16,9-20).

La nostra pericope si trova nella prima parte del Vangelo che può essere suddivisa, a sua volta, in tre sezioni ${ }^{126}$ : 1) $1,16-3,12$; 2) 3,13-6,6; 3) 6,7-8,26. Tutte e tre le sezioni si aprono con una scena in cui vi sono i discepoli: 1,16-20 parla della loro vocazione; 3,13-19 riferisce l'istituzione dei Dodici; 6,7-13 parla della missione dei discepoli. Verso la fine di ogni sezione si trova un'informazione sulla risposta negativa alla persona di Gesù: in 3,1-6 lo rifiutano i farisei e gli erodiani; in 6,1-6a non lo capisce né la sua famiglia né i suoi compaesani; in $8,14-21$ neanche i suoi discepoli lo capiscono. Le prime due sezioni si concludono

123 Nel commento di Moloney possiamo leggere: "Following an episode during which Jesus ace cursed his disciples of blindness (see v. 18a), the miracle tells of a man who moves from no sight (v. 22), to a limited vision (vv. 23-24), to full sight (v. 25), before being dismissed from the scene (v. 26). The passage looks back to the blindness of the disciples (v. 18), and forward to the episode which follows, closing the first half of the Gospel, where two of these stages of "sight" will be realized (8:27-30)" (Moloney, The Gospel of Mark, 163).

124 Cfr. Haręzga, Jezus i Jego uczniowie, 197.

125 Per conoscere i diversi modi di suddividere il Vangelo secondo Marco cfr. per es. J. Verheyden, "Trouble at Bethsaida. Some Comments on the Interpretation and Location of Mark 8,22-26 within the Gospel", La surprise dans la Bible, Hommage à Camille Focanti (ed. G. Van Oyen - A. Wénin) (Bibliotheca Ephemeridum Theologicarum Lovaniensium 247; Leuven - Paris Walpole, MA: Uitgeverij Peeters 2012) 209-213. Nella nostra suddivisione del Vangelo ci allineiamo per es. a D.A. Koch, "Inhaltliche Gliederung und geographischer Aufriss im Markusevangelium”, New Testament Studies 29 (1983) 157-158.

126 Questa suddivisione si trova per esempio in: Guelich, Mark 1-8:26, 316-318. 
con un sommario sulla natura del mistero di Gesù: 3,7-12: Gesù guarisce le folle; 6,6b: Gesù va in giro per i villaggi e insegna. Nel luogo in cui andrebbe collocato il terzo riepilogo, vale a dire alla fine della terza sezione, si trova proprio il nostro brano sulla guarigione del cieco. Anzi, trovandosi alla fine della prima parte del Vangelo, il brano può esser considerato come un riepilogo di tutta la parte e allo stesso tempo come una transizione verso la II parte del Vangelo di Marco ${ }^{127}$.

Sulla base di quanto è stato appena detto possiamo affermare che la I parte del Vangelo di Marco si presenta secondo lo schema seguente ${ }^{128}$ :
A) $1,16-3,12$
1,16-20: la vocazione dei discepoli,
3,1-6: la risposta negativa dei farisei e degli erodiani,
3,7-12: sommario: Gesù guarisce le folle.
B) 3,13-6,6
3,13-19: l'istituzione dei Dodici,
6,1-6a: la risposta negativa dei compaesani,
6,6b: sommario: Gesù cammina e insegna,
C) $6,7-8,26$
6,7-13: la missione dei Dodici,
$8,14-21$ : la risposta negativa dei suoi discepoli,
8,22-26: sommario (?), cioè la guarigione del cieco.

Il nostro schema evidenzia il ruolo particolare svolto dai discepoli di Gesù. D'altra parte, anch'essi appartengono al gruppo di persone che non capisce il mistero di Gesù: prima (come abbiamo visto) Gesù viene rifiutato dai farisei e degli erodiani, poi dai suoi compaesani; infine non lo capiscono neanche i suoi discepoli $(8,14-21)$. Nella I parte di Mc ci sono anche altri brani in cui si parla dell'incomprensione dei discepoli ${ }^{129}$. In 8,14-21, Gesù mostra direttamente ai suoi discepoli la loro incapacità di capire. Prendendo in considerazione l'incomprensione dei discepoli in tutte e tre le sezioni della I parte, possiamo tracciare lo schema seguente:

127 Guelich scrive: "The healing of the blind man in phases sums up Jesus' ministry with reference to the disciples and serves as the transition to that same theme underlying the second half of the Gospel" (Guelich, Mark 1-8:26, 316).

128 Cfr. Guelich, Mark 1-8:26, 316-318.

129 In Mc 4,10 i discepoli non capiscono le parabole; in Mc 4,41 (dopo la tempesta sedata) domant dano chi è Gesù; in Mc 6,34-44 non sanno come dare da mangiare alle folle; in Mc 6,45-51 cominciano a gridare dalla paura, vedendo che Gesù cammina sulle acque; in Mc 6,52 si dice ancora una volta che non hanno capito il fatto dei pani; in Mc 7,17 non capiscono l'insegnamento sul puro e sull'impuro; in Mc 8,1-9 non sanno come si potrebbero sfamare le folle nel deserto. 


\begin{tabular}{|l|l|}
\hline \multicolumn{1}{|c|}{ La sezione della I parte di Mc } & \multicolumn{1}{c|}{ L'incomprensione dei discepoli } \\
\hline A) $1,16-3,12$ & \\
\hline B) $3,13-6,6$ & $4,10 \mathrm{a}$ \\
& 4,41 \\
\hline C) $6,7-8,26$ & $6,34-44$ \\
& $6,45-51$ \\
& 7,17 \\
& $8,1-9$ \\
& $8,14-21$ \\
\hline
\end{tabular}

Nella I sezione non si parla dell'incomprensione dei discepoli; nella II - soltanto due volte; nella III invece molto più spesso torna il tema dell'incapacità di capire la missione di Gesù da parte dei suoi discepoli. Lo schema ci mostra che l'incomprensione cresce fino a culminare in Mc 8,21 in cui Gesù domanda:

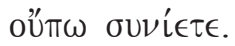

La II parte di Mc $(8,27-16,8)$ comincia con il cammino di Gesù verso Gerusalemme $(8,27-10,52)$, dedicato in modo particolare ai discepoli. Le folle quasi scompaiono, le altre persone che non appartengono ai Dodici sono poche (l'epilettico: 9,14-27; i bambini: 10,13-16; l'uomo ricco: 10,17-22; il cieco: 10,46-52); nella maggior parte del cammino sono soltanto i discepoli a restare con Gesù. Anche in questa sezione viene messa in luce l'incomprensione dei discepoli. Basta dire che sempre, dopo le tre predicazioni della passione di Gesù $(8,31$; 9,31; 10,33-34) segue l'incapacità di capire da parte dei discepoli. È interessante che, in questa sezione, anche l'attività di Gesù è cambiata ${ }^{130}$. Soltanto una volta scaccia il demonio $(9,14-29)$ e soltanto una volta guarisce il cieco $(10,46-52)$.

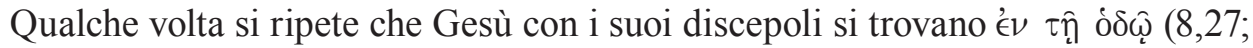
$9,33-34 ; 10,17.32 .52)$ per sottolineare che il senso del discepolato sta proprio nel cammino, nella strada verso Gerusalemme. Dapprima in modo implicito, ricorrendo a delle allusioni $(2,20)$, poi più apertamente, Gesù può annunziare la sua passione, spiegando anche qualche volta cosa significherà la missione del Messia quando entreranno a Gerusalemme (8,31; 9,12.31; 10,33-34.38.45). Nel mistero della passione e della croce è inserito non soltanto Gesù, ma anche coloro che lo seguono, cioè anzitutto i suoi discepoli $(8,34-9,1 ; 10,30.39)$. Adesso, in questa sezione, il mistero della croce viene posto esplicitamente davanti agli occhi dei discepoli.

Pensando al contributo della nostra pericope al messaggio dell'intero Vangelo, non possiamo trascurare la somiglianza di 8,22-26 con 7,31-37, cioè con la guarigione di un sordomuto. Tutte e due le storie sono costruite secondo

130 Cfr. France, The Gospel of Mark, 320. 
lo stesso schema: un malato viene portato da altri a Gesù con la richiesta che Gesù lo tocchi $(7,33 ; 8,22)$; Gesù lo prende in disparte lontano dalla folla $(7,33 a$; $8,23 \mathrm{a})$ e comincia il processo di guarigione con l'uso della saliva (7,33b; $8,23 \mathrm{~b})$;

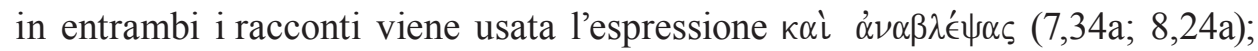
ambedue finiscono con un ordine di Gesù $(7,36 ; 8,26)^{131}$. Tra questi due racconti ci sono anche alcune differenze: sono diverse le malattie, Gesù tocca con le sue mani diverse parti del corpo dei malati; nella prima guarigione non deve ripetere il gesto dell'imposizione delle mani - la guarigione arriva subito. Gli elementi comuni ci invitano a fare un raffronto tra le due storie; le differenze invece ci consentono di trattare i due racconti come episodi distinti nella narrazione marciana. Nonostante le differenze, si vede chiaramente che anche la tematica della prima guarigione si inserisce molto bene nel nostro contesto. Un sordomuto - l'incapacità di sentire e parlare - e poi (nel capitolo successivo) un cieco - l'incapacità di vedere - tutte queste 'mancanze' rientrano bene nella tematica della relazione dei discepoli con Gesù.

Dopo averpresentatola struttura del Vangelo di Marco e formulato le nostre osservazioni al riguardo, possiamo adesso giungere alle conclusioni, focalizzandoci sul contributo della nostra pericope al messaggio dell'intera opera marciana.

1. La guarigione del cieco si trova proprio alla fine della I parte del Vangelo di Marco, dedicata alla missione di Gesù in Galilea; ed è collegata anche con il brano successivo $(8,27-30)$, facendo in questo modo da ponte tra la I e la II parte del vangelo, vale a dire tra la missione in Galilea ed il cammino verso Gerusalemme ${ }^{132}$.

2. Il racconto sulla guarigione del cieco si trova a sua volta alla fine della III sezione della I parte del Vangelo. In questa III sezione si parla talvolta (più spesso che nelle altre sezioni) dell'incapacità dei discepoli di capire l'identità di Gesù e la sua missione.

3. La nostra pericope, insieme con la guarigione del sordomuto, costruisce una cornice ${ }^{133}$, al centro del cui quadro vi sono i discepoli che non capiscono

131 Per approfondire questo raffronto cfr.: R.M. Fowler, Loaves and Fishes. The function of the Feeding Stories in the Gospel of Mark (SBL Dissertation Series 54; Ann Arbor, MI 1981) 105108.

132 Alcuni commentari arrivano a questa conclusione: "The Blind Man of Betsaida is none other than St Peter, whose eyes were opened near Cesarea Philippi" (A. Richardson, The Miracle Stories of the Gospels (London: SCM Press 1941) 86). Secondo Eve ("Spit in Your Eye", 12), la guarigione di un cieco serve da commento per la scena successiva (8,27-30): "Peter's confession of Jesus as Messiah is analogous to the blind man's perception of people as walking trees".

133 Fowler sottolinea: "The key [...] is the recognition that the major function of 7:31-37 and 8:22-26 in the Mark is to frame the intervening verses in 8:1-21, the culmination of which is a devastating criticism by Jesus of the disciples' stupidity, expressed principally in terms of a failure to 'see' and to 'hear' (8:18). In contradistinction to the healed men in 7:31-37 and 8:22-26, the disciples persist in their deafness, dumbness, and blindness" (Fowler, Loaves and Fishes 108). 
nulla. Questo quadro viene intitolato in 8,18: Avete occhi e non vedete, avete orecchi e non udite? e poi in 8,21: Non capite ancora?

4. L'apertura degli occhi non può non farci pensare all'Antico Testamento, particolarmente ai testi profetici di Is 29,$18 ; 35,5 ; 42,7$. Queste profezie dicono che l'apertura degli occhi viene strettamente collegata con la potenza liberatrice di Dio, esercitata in quel giorno (Is 29,18). La guarigione diventa un segno della ricompensa divina (Is 35,4). Tutti i miracoli manifestano la potenza dell'opera redentrice di Dio. È molto significativo il testo di Is 42,7, dal primo canto del servo del Signore; adesso i segni della potenza liberatrice di Dio vengono trasmessi nelle mani del suo servo: perchè tu apra gli occhi ai ciechi. La potenza di aprire gli occhi non era consentita a nessun profeta dell'Antico Testamento; era riservata soltanto a Dio. Nella nostra pericope, Mc 8,22-26, diventa anche un segno della divinità di Gesù-Messia ${ }^{134}$.

5. Soltanto in Mc 8,22-26, il miracolo della guarigione del cieco richiede due momenti, due imposizioni delle mani da parte di Gesù. Non c'è nessun altro miracolo raccontato in questo modo. Il suo significato, nel Vangelo di Marco, è chiaramente simbolico ${ }^{135}$. La vista alquanto obnubilata del malato corrisponde alle risposte dei discepoli riguardo all'identità di Gesù in 8,27-30. La seconda imposizione delle mani corrisponde alla seconda domanda in 8,29. Ma la conclusione delle due storie è totalmente diversa: il cieco recupera la vista, può vedere chiaramente ed a distanza ogni cosa; i discepoli invece, nonostante la ripetizione della domanda e nonostante tutto ciò che avevano visto in Galilea e poi nei territori pagani, non riescono a vedere chi è Gesù ${ }^{136}$. La loro miopia è più grave della miopia dell'uomo guarito. Pietro riconosce l'identità di Gesù, ma soltanto per un momento. Poi ridiventa di nuovo cieco, prendendo Gesù in disparte e non concorda con la predicazione della sua passione e morte. L'incapacità di capire da parte dei discepoli si aggrava ancor più. Potremmo dire che essi passano dalla miopia (le prove di dare le risposte su chi è Gesù) alla cecità satanica ${ }^{137}$, quando negano la sua missione della passione e della croce. Il dialogo con Gesù (in 8,27-9,1) non ha aperto loro gli occhi. La loro cecità spirituale è persino più grave della cecità fisica. La guarigione dell'uomo cie-

134 K.W. Larsen, "A Focused Christological Reading of Mark 8:22-9:13", TRINJ 26 (2005) 37.

135 Si parla dei tre simboli nella scena della guarigione: 1) la cecità fisica come simbolo della cecità spirituale, 2) l'uomo cieco come simbolo del discepolo di Gesù, 3) le due tappe del miracolo come simbolo del processo della guarigione spirituale che conduce verso la comprensione della missione di Gesù. Vedi: T. Wiarda, "Scenes and Details in the Gospels: Concrete Reading and Three Alternatives", NTS 50 (2004) 174.

136 Larsen scrive: "They have seen his miracles, they have heared him teach, but their understanding will be blury and incomplete until Jesus gives the final piece" (Larsen, "A Focused Christological Reading", 41).

137 J.F. Williams, Other Followers of Jesus. Minor Characters as Major Figures in Mark's Gospel (JSNT 102; Sheffield: Academic Press 1994) 131. 
co esprime la necessità di un percorso dalla vista parziale alla vista completa anche a livello spirituale. E questo cambiamento è tutt'altro che facile: da solo, l'uomo non riesce ad aprire gli occhi. Ha bisogno dell'incontro con Gesù e del suo tocco particolare, nell' intimità, fuori dal villaggio. Malgrado la difficoltà dei discepoli di apriregli occhi dello spirito, la guarigione del cieco vicino a Betsaida ci offre una speranza e un incoraggiamento: l'apertura degli occhi è possibile anche quando i discepoli non capiscono ancora $(8,21)$. Per aprire gli occhi dello spirito ci vuole un altro miracolo, il più grande di tutti. La vista dei discepoli sarà guarita pienamente solo dopo la risurrezione di Gesù. Marco non vuol dare una falsa immagine della facilità della fede, ma con il miracolo della guarigione del cieco vuole preparare i suoi lettori all'importanza del messaggio pasquale. Gli occhi si aprono pienamente dopo la risurrezione, confermata la mattina di Pasqua dal giovinetto presso la tomba vuota: $\alpha$ ưtòv ő $\psi \in \sigma \theta \in(16,7)$.

\section{Conclusione}

Riassumendo la nostra analisi del racconto di Mc 8,22-26, osserviamo che questa pericope occupa un posto importante sia per la struttura che per il messaggio dell'opera marciana. Esso infatti si trova al centro di tutto il Vangelo del Nostro, alla fine della I parte e serve come da passaggio verso la II parte. Il significato del nostro brano deriva anche dal contenuto, sintetizzabile in due parti:

L'importanza dell'aspetto cristologico: Gesù si rivela - e non è la prima volta - come un taumaturgo, più potente delle malattie dell'uomo. Con l'uso della saliva e l'imposizione delle mani è in grado di aprire gli occhi del cieco. Il collocamento del miracolo prima della partenza per il nord inserisce questo evento nel cammino di Gesù che conduce alla passione. All'apertura degli occhi del cieco va attribuito un significato simbolico. Soltanto Gesù può aiutare tutti coloro che vogliono ottenere occhi che vedono, cioè sono capaci di comprendere con la fede la sua parola e riconoscere veramente la sua identità.

Il discepolato in rapporto a Gesù: L'esperienza dell'apertura degli occhi costituisce un passo nuovo e significativo nel rapporto tra Gesù e i discepoli. La loro presenza silenziosa dà la possibilità di sperimentare la potenza di Gesù. D'altra parte si vede che i discepoli rimangono ancora fuori del suo mistero. Poco prima è stato mosso loro il rimprovero degli occhi ciechi: Avete occhi e non vedete $(8,18)$ e non capite ancora? $(8,21)$. Il collocamento della scena prima della professione di fede di Pietro $(8,30)$ e della successiva istruzione dei discepoli sulla necessità della passione e della croce indica che Gesù vuol aprire gli occhi non soltanto al nostro cieco ma anche ai suoi discepoli. Le due fasi della guarigione indicano che il passaggio dalla cecità alla vista chiara e completa è tutt'altro 
che facile e deve esserci perciò una fase intermedia: il momento della miopia, quando cioè si vede, ma non ancora in modo chiaro e distinto. La miopia dei discepoli sarà anch'essa superata, ma solo più tardi.

Tutto ciò significa che la sequela di Gesù non è un percorso agevole bensì un cammino che comporta rischi, momenti di fede non ben chiara e sicura. L'esperienza del cieco - totalmente passivo nel nostro racconto - sottolinea in che cosa si esprime la fede: fidarsi totalmente di Gesù, il Messia, farsi portare dagli altri che possono farci avvicinare a lui ed alla sua potenza guaritrice.

Marco scrive alla prima comunità di cristiani e vuole avvisarli del pericolo di una falsa visione di Gesù. Il discepolo-testimone di Cristonon è solo chi riceve la sua benedizione, ma chi prende il Vangelo per portarlo in tutto il mondo nonostante le difficoltà ${ }^{138}$. La croce diventa sempre una sfida e uno scandalo. Come per i discepoli di Gesù nel Vangelo, la passione diventa sempre più difficile da accettare, così anche per la comunità marciana poteva essere era difficile proclamare Gesù che doveva portare la croce. La guarigione del cieco, svolta in due fasi, è nel Vangelo come una prefigurazione della realtà che sarebbe venuta attesa per un momento successivo. La comprensione del mistero di Gesù non arriva subito, richiede del tempo; sono necessarie diverse fasi e processi. Nel caso dei discepoli storici di Gesù, la seconda fase della guarigione - l'apertura dei loro occhi - non viene descritta nel Vangelo. Essa arriva più tardi, dopo la risurrezione.

\section{Bibliografia}

Appold, M., "The Mighty Works of Bethsaida: Witness of the New Testament and Related Traditions", Bethsaida: A City by the North Sea of Galilee (ed. R. Arav - R.A. Freund) (Bethsaida Excavations Project 1; Kirksville, MO: Thomas Jefferson University Press: 1995) 229-242.

Balz, H. - Schneider, G., Dizionario Esegetico del Nuovo Testamento (Brescia: Paideia 1998) $(=D E N T)$.

Bauer, W. - Gingrich, F.W. - Danker, F.W., A Greek - English Lexicon of the New Testament and Other Early Christian Literature (Chicago - London: The University of Chicago Press 1979).

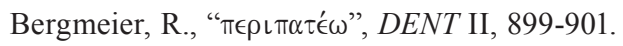

Best, E., Following Jesus. Discipleship in the Gospel of Mark (Journal for the Study of the New Testament. Supplement Series 4; Sheffield: JSOT Press 1981).

Blass, F. - Debrunner, A. - Rehkopf, F., Grammatica del greco del Nuovo Testamento (Brescia: Paideia ${ }^{2}$ 1997) $(=B D R)$.

Boyd, W.J.P., "Is a Basis of Fact Discernible in the Miracle Story of the Healing of the Blind Man at Bethsaida (Mk viii. 22-26)?", Papers presented to the Fifth International Congress on

138 E. Best, Following Jesus. Discipleship in the Gospel of Mark (JSNT 4; Sheffield: JSOT Press 1981) 136. 
Biblical Studies held at Oxford, 1973 (ed. E.A. Livingstone) (Studia Evangelica VII; Berlin: Akademie Verlag 1982) 83-85.

Derrett, J.D.M., “Trees Walking, Prophecy, and Christology”, Studia Theologica 35 (1981) 33-54.

Eckey, W., Das Markusevangelium. Orientierung am Weg Jesu. Ein Kommentar (Neukirchen:

Neukirchener Verlag 1998).

Edwards, J.R., The Gospel according to Marc (Grand Rapids, MI - Cambridge, UK: Eerdmans 2002).

Ernst, J., Il vangelo secondo Marco (Brescia: Morcelliana 1991).

Eve, E., "Spit in Your Eye: The Blind Man of Bethsaida and the Blind Man of Alexandria", New Testament Studies 54 (2008) 1-17.

Fowler, R.M., Loaves and Fishes. The Function of the Feeding Stories in the Gospel of Mark (SBL Dissertation Series 54; Ann Arbor, MI: Scholars Press1981).

France, R.T., The Gospel of Mark. A Commentary on the Greek Text (The New International Greek Testament Commentary; Grand Rapids, MI - Cambridge, U.K.: Eerdmans 2002).

Freedman, D.N. (ed.), The Anchor Bible Dictionary (New York: Doubleday 1992) I-VI (=ABD).

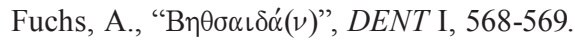

Gerber Ayayo, K., "Magical Expectations and the Two-Stage Healing of Mark 8", Bulletin for Biblical Research 24/3 (2014) 379-391.

Gianattilio, B., Personaggi minori e discepoli in Marco 4-8. La funzione degli episodi dei personaggi minori nell'interazione con la storia dei protagonisti (Analecta Biblica 73; Roma: Editrice Pontificio Istituto Biblico 2008).

Glenney, B. - Noble, J.T., "Perception and Prosopagnosia in Mk 8.22-26", Journal for the Study of the New Testament 37 (2014) 71-85.

Gnilka, J., Marco (Assisi: Cittadella 1987).

Greeven, H. - Güting, E. (ed.), Textkritik des Markusevangeliums (Münster: LIT Verlag 2005).

Greeven, H., "Mk 8,23. Analyse der Textüberlieferung”, Textkritik des Markusevangeliums (ed. H. Greeven - E. Gütig) (Münster: LIT Verlag 2005) 415;

--------, "Mk 8,25. Analyse der Textüberlieferung", Textkritik des Markusevangeliums (ed. H. Greeven - E. Gütig) (Münster: LIT Verlag 2005) 418.

Guelich, R.A., Mark 1-8:26 (Word Biblical Commentary 34A; Dallas, TEX: Word Books Publisher 1989).

Gundry, R.H., Mark. A Commentary on His Apology for the Cross (Grand Rapids, MI: Eerdmans 1993).

Haręzga, S., Jezus i Jego uczniowie. Model chrześcijańskiej formacji w Ewangelii wedtug św. Marka (Lublin: Wydawnictwo KUL 2007).

Howard, J.K., "Men as Trees, Walking: Mark 8.22-26", Scottish Journal of Theology 37 (1984) 163-170.

Johnson, E.S., "Mark VIII.22-26: The Blind Man from Bethsaida", New Testament Studies 25 (1978/1979) 370-383.

Koch, D.A., "Inhaltliche Gliederung und geographischer Aufriss im Markusevangelium”, New Testament Studies 29 (1983) 145-166.

Larsen, K.W., “A Focused Christological Reading of Mark 8:22-9:13”, Trinity Journal 26 (2005) 33-46.

Légasse, S., Marco (Roma: Borla 2000).

Malina, A., Ewangelia wedtug świętego Marka: 1,1-8,26. Wstęp, przekład z oryginału, komentarz (Nowy Komentarz Biblijny. Nowy Testament II/1; Częstochowa: Edycja Świętego Pawła 2013). Marcus, J., “A Note on Markan Optics”, New Testament Studies 45 (1999) 250-256. 
Metzger, B.M. (ed.) The Greek New Testament (Stuttgart: Deutsche Bibelgesellschaft ${ }^{5} 2001$ ).

Metzger, B.M., A Textual Commentary on the Greek New Testament (Stuttgart: Deutsche Bibelgesellschaft $\left.{ }^{2} 2001\right)$.

Miller, J.I., "Was Tischendorf Really Wrong? Mark 8:26b Revisited", Novum Testamentum 28 (1986) 97-103.

Miller, C.H. - Wojciechowski, M., "Betsaida”, Encyklopedia biblijna (ed. P.J. Achtemeier) (Warszawa: Vocatio 2004) 97-98.

Moloney, F.J., The Gospel of Mark. A Commentary (Peabody: Hendrickson Publishers 2002).

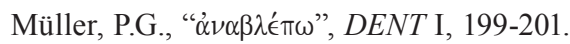

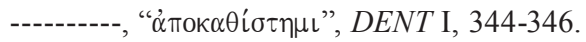

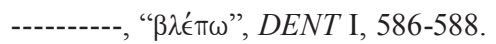

Myers, C., Binding the Strong Man. A political Reading of Mark's Story of Jesus (Maryknoll, NY: Orbis Books 1988) 240.

Richardson, A., The Miracle - Stories of the Gospels (London: SCM Press 1941).

Ross, J.M., "Another Look at Mark 8:26", Novum Testamentum 29 (1987) 97-99.

Salvatore, E., E vedeva a distanza ogni cosa. Il racconto della guarigione del cieco di Betsaida (Mc 8,22-26) (Roma - Brescia: Editrice Pontificia Università Gregoriana 2003).

Schenk, W., "€ $\rho \omega \tau \alpha \dot{\omega} \omega ”, ~ D E N T ~ I, ~ 1392-1394$.

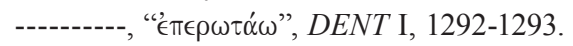

Stock, K., Marco. Commento contestuale al secondo Vangelo (Roma: Apostolato della Preghiera 2003).

Strange, J.F., "Beth-saida", $A B D$ I, 692-693.

Thomas, J., „ா $\alpha \rho \alpha \kappa \alpha \lambda \lambda^{\prime} \omega$ “, DENT II, 767-777.

Vattioni, F. (ed.), La Bibbia di Gerusalemme (Bologna: EDB 2004).

Verheyden, J., "Trouble at Bethsaida. Some Comments on the Interpretation and Location of Mark 8,22-26 within the Gospel”, La surprise dans la Bible, Hommage à Camille Focanti (ed. G. Van Oyen - A. Wénin) (Bibliotheca Ephemeridum Theologicarum Lovaniensium 247; Leuven - Paris - Walpole, MA: Uitgeverij Peeters 2012) 209-232.

Wiarda, T., "Scenes and Details in the Gospels: Concrete Reading and Three Alternatives", New Testament Studies 50 (2004) 167-184.

Williams, J.F., Other Followers of Jesus. Minor Characters as Major Figures in Mark's Gospel (Journal for the Study of the New Testament. Supplement Series 102; Sheffield: Academic Press 1994). 